ARTICLE

\title{
CCN1 is an opsonin for bacterial clearance and a direct activator of Toll-like receptor signaling
}

Joon-II Jun (iD) ${ }^{1} \&$ Lester F. Lau (iD) ${ }^{1 \times}$

Expression of the matricellular protein CCN1 (CYR61) is associated with inflammation and is required for successful wound repair. Here, we show that CCN1 binds bacterial pathogenassociated molecular patterns including peptidoglycans of Gram-positive bacteria and lipopolysaccharides of Gram-negative bacteria. CCN1 opsonizes methicillin-resistant Staphylococcus aureus (MRSA) and Pseudomonas aeruginosa and accelerates their removal by phagocytosis and increased production of bactericidal reactive oxygen species in macrophages through the engagement of integrin $\alpha_{v} \beta_{3}$. Mice with myeloid-specific $\operatorname{Ccn} 1$ deletion and knock-in mice expressing CCN1 unable to bind $\alpha_{v} \beta_{3}$ are more susceptible to infection by $S$. aureus or $P$. aeruginosa, resulting in increased mortality and organ colonization. Furthermore, CCN1 binds directly to TLR2 and TLR4 to activate MyD88-dependent signaling, cytokine expression and neutrophil mobilization. CCN1 is therefore a pattern recognition receptor that opsonizes bacteria for clearance and functions as a damage-associated molecular pattern to activate inflammatory responses, activities that contribute to wound healing and tissue repair. 
T he rapid emergence of antibiotic-resistant bacteria poses a serious threat to public health globally ${ }^{1}$. Despite the remarkable success of antibiotics in treating bacterial infections since the 1940s, resistance to virtually all available antibiotics has been observed in recent decades. Antibioticresistant bacterial infections account for nearly 3 million clinical cases and $>35,000$ deaths annually in the United States alone ${ }^{2}$, and $>700,000$ deaths worldwide ${ }^{3}$. Among the most encountered pathogens are the Gram-positive Staphylococcus aureus (S. aureus) and the Gram-negative Pseudomonas aeruginosa (P. aeruginosa). These bacteria quickly acquire antibiotic resistance, largely through mobile genetic elements such as plasmids and transposons ${ }^{4}$. Methicillin-resistant S. aureus (MRSA) alone accounts for a large portion of nosocomial ${ }^{5}$ and communityacquired infections ${ }^{6}$ and is a leading cause of endocarditis, septicemia, and skin and soft-tissue infections $(\mathrm{SSTIs})^{7,8} . P$. aeruginosa is an opportunistic pathogen commonly found in ventilator-associated pneumonia, catheter-associated urinary tract infections, burn wounds, and blood infections ${ }^{9}$. Although vaccines are under development for these pathogens, none have achieved clinical efficacy to date ${ }^{10,11}$. Therefore, there is an urgent need to identify effective therapeutic strategies for such antibioticresistant pathogens as $S$. aureus and P. aeruginosa.

Upon bacterial infection, vertebrate hosts mount an onslaught of attacks at the invaders, including activation of the complement system that targets bacteria for lysis or phagocytosis. In addition, resident macrophages that patrol the tissues eliminate microbes by phagocytosis, whereupon the activated macrophages produce cytokines and chemokines to induce inflammation and to recruit immune cells that reinforce bacterial removal and initiate adaptive immunity ${ }^{12}$. Accordingly, defects in phagocytes lead to impaired host defense against infections ${ }^{13}$. Bacterial pathogens are typically detected by host proteins known as pattern recognition receptors (PRRs) that recognize and bind distinct microbial components, or pathogen-associated molecular patterns $(\mathrm{PAMPs})^{14}$. Among the best characterized PRRs are cell surface Toll-like receptors (TLRs), which are potent activators of inflammatory responses upon recognition of PAMPs ${ }^{15,16}$. TLRs can also mediate sterile inflammation by interacting with damage-associated molecular patterns (DAMPs), endogenous danger molecules that are released from damaged or dying cells ${ }^{17,18}$. Professional phagocytes express PRRs that bind PAMPs and induce phagocytosis directly, such as macrophage mannose receptor and macrophage scavenger receptors 19,20 , as well as opsonins that recognize PAMPs and connect the bacteria to phagocytes for elimination ${ }^{21,22}$. As these mechanisms of host defenses are unrelated to the bactericidal pathways of antibiotics, treatments that stimulate or enhance these host defenses may provide therapeutic strategies for the clearance of microbial pathogens irrespective of their antibiotic resistance status.

Ccn1 (Cyr61) encodes a $40 \mathrm{kDa}$ matricellular protein that is essential for embryonic development ${ }^{23,24}$. In adults, $C c n 1$ expression is associated with inflammation and is required for successful injury repair in the $\operatorname{skin}^{25,26}$, liver ${ }^{27}$, and gut $^{28}$. Structurally, CCN1 is organized into four conserved domains with homologies to insulin-like growth factor-binding protein (IGFBP), von Willebrand factor type C repeat (vWC), thrombospondin type-1 repeat (TSR), and a cysteine-knot motif in the C-terminal (CT) domain (Supplementary Fig. 1) ${ }^{29}$. Mechanistically, CCN1 acts through direct binding to specific integrin receptors in a cell type-specific manner, engaging coreceptors in some contexts ${ }^{30,31}$. The specific CCN1-binding sites for several integrin receptors, including $\alpha_{v} \beta_{3} / \alpha_{v} \beta_{5}, \alpha_{6} \beta_{1}$, and $\alpha_{M} \beta_{2}$, have been identified $^{29,30}$.

We have recently shown that $\mathrm{CCN} 1$ promotes efferocytosis, or phagocytosis of apoptotic cells, by binding phosphatidylserine, the "eat-me" signal on apoptotic cells and bridging them to macrophages for elimination through engagement of the phagocytic receptor, integrin $\alpha_{v} \beta_{3}{ }^{25}$. Consequently, CCN1 stimulates the removal of apoptotic neutrophils and accelerates wound healing progression. Here, we have found that $\mathrm{CCN} 1$ functions as an opsonin for bacterial clearance through specific binding to PAMPs of $S$. aureus and $P$. aeruginosa, inducing their phagocytic elimination through engagement of integrin $\alpha_{v} \beta_{3}$ on phagocytes. Additionally, $\mathrm{CCN} 1$ enhances bacterial killing in macrophages by increasing the production of bactericidal reactive oxygen species (ROS). Independent of its opsonin activity, CCN1 can also directly bind and activate TLR2 and TLR4 to induce the expression of proinflammatory cytokines in a MyD88-dependent manner. Altogether, these results show that CCN1 is a PRR that induces opsonophagocytosis of bacteria and a DAMP that can trigger sterile inflammation through activating TLR signaling.

\section{Results}

CCN1 binds $S$. aureus and $P$. aeruginosa through PAMPs. Based on the finding that $\mathrm{CCN} 1$ induces efferocytosis of apoptotic neutrophils ${ }^{25}$, we investigated the possibility that $\mathrm{CCN} 1$ may also target bacterial pathogens for removal by phagocytosis, an activity that requires specific recognition of bacterial PAMPs. Thus, we first assessed whether $\mathrm{CCN} 1$ can recognize and bind the Grampositive $S$. aureus and the Gram-negative $P$. aeruginosa in a solidphase-binding assay. Indeed, $S$. aureus showed efficient binding to immobilized CCN1, with half-maximal binding occurring at $\sim 10$ pmol per well CCN1 (Fig. 1a). Soluble CCN1 also bound $S$. aureus efficiently as observed by flow cytometry (Supplementary Fig. 2). S. aureus can bind various host extracellular matrix (ECM) proteins by expressing bacterial adhesins, including the fibronectin-binding protein $(\mathrm{FnBP})^{32}$, although the specific $S$. aureus strain (MRSA USA300) used in this study does not express the collagen adhesin (Cna) ${ }^{33}$. Consistently, S. aureus bound immobilized fibronectin (FN) in a dose-dependent manner with half-maximal binding at $\sim 20 \mathrm{pmol}$ per well but failed to bind collagen I (Col1 $\alpha 1$; Fig. 1a). Both the CCN1-D125A mutant protein $^{34}$, which is unable to bind integrins $\alpha_{v} \beta_{3} / \alpha_{v} \beta_{5}$ as a result of a single amino acid substitution (Asp125 to Ala), and the CCN1-DM mutant ${ }^{35}$, which is defective for binding integrins $\alpha_{6} \beta_{1} / \alpha_{M} \beta_{2}$, were able to bind $S$. aureus with affinities similar to that of wild type (WT) CCN1 (Fig. 1b). Thus, the CCN1-binding site(s) for $S$. aureus are distinct from those for integrins $\alpha_{v} \beta_{3} / \alpha_{v} \beta_{5}$ and $\alpha_{6} \beta_{1} / \alpha_{M} \beta_{2}$.

We endeavored to identify the region of CCN1 responsible for binding S. aureus using a series of deletion mutants (Supplementary Fig. 1). Mutants that contain the TSR domain ( $\triangle \mathrm{CT}$ and TSR alone) showed as strong binding to $S$. aureus as CCN1-WT, whereas mutants containing the vWC domain (IGFBP-vWC and vWC alone) displayed strong to moderate binding (Fig. 1c). However, the IGFBP domain alone did not bind $S$. aureus. These results suggest that CCN1 binds $S$. aureus through the TSR and vWC domains, whereas the CT domain is dispensable (Fig. 1c). Prominent among PAMPs of Gram-positive bacteria are the cell wall components peptidoglycan (PGN) and lipoteichoic acid (LTA). We found that CCN1 proteins (WT, D125A, or DM) bound to immobilized PGN, but not LTA (Fig. 1g). Immunoblotting also showed that both the vWC and TSR domains could bind PGN individually, but not the IGFBP domain (Supplementary Fig. 3). These results demonstrate that CCN1 directly binds S. aureus through its $\mathrm{vWC}$ and TSR domains by recognizing PGN, a bacterial PAMP.

CCN1 also exhibited strong binding to $P$. aeruginosa in a dosedependent manner, with half-maximal binding at $\sim 20$ pmol per well CCN1 (Fig. 1d). Other ECM proteins, including FN, LN, and 

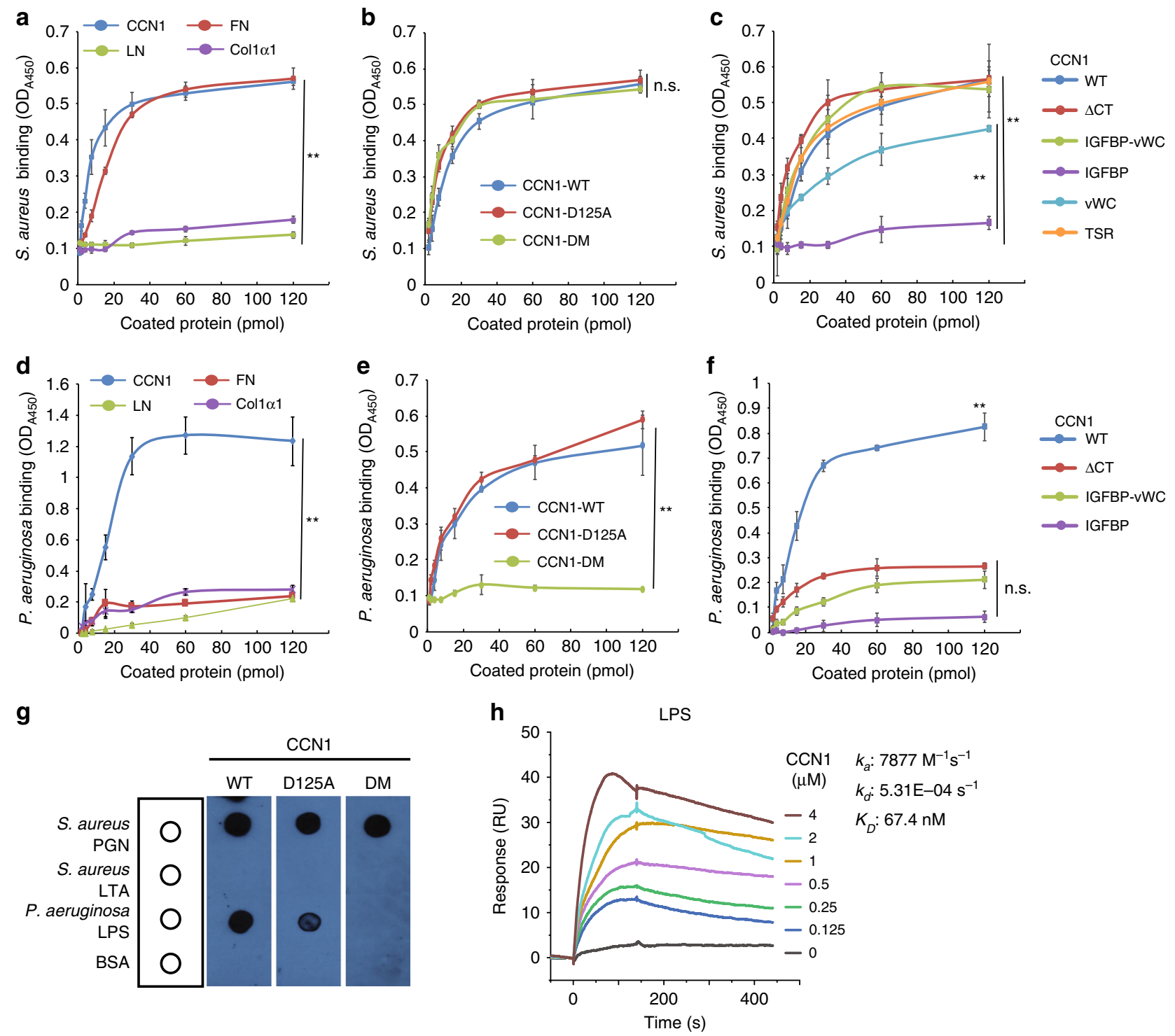

Fig. 1 CCN1 binds S. aureus and $\mathbf{P}$, aeruginosa through PGN and LPS, respectively. CCN1 binding to $S$. aureus (a-c) and $P$. aeruginosa (d-f) was evaluated using a solid-phase-binding assay. a S. aureus bound to surfaces coated with CCN1-WT or other ECM proteins (FN fibronectin, LN laminin, Col1a1 collagen type I) was quantified using polyclonal anti-S. aureus antibodies. CCN1 and FN bound to S. aureus, whereas LN and Col1 1 1did not. b Binding assay of S. aureus to recombinant CCN1-WT, CCN1-D125A, and CCN1-DM proteins as above. c Binding of S. aureus to CCN1 deletion mutant proteins as above. d Solid-phase-binding assays for $P$. aeruginosa were performed as above and detected with polyclonal anti-P. aeruginosa antibodies. e Binding assay showing $P$. aeruginosa binding to CCN1-WT and CCN1-D125A, but not CCN1-DM. f Solid-phase-binding assays with CCN1 deletion mutants. All assays were done in triplicates and data are expressed as mean \pm s.d. Statistical evaluation was performed by one-sided, two-sample with equal variance $t$-tests. ${ }^{\star \star} p<0.01$, n.s. = not significant. $\mathbf{g}$ Bacterial molecular patterns (PGN of S. aureus; LTA of S. aureus; LPS of P. aeruginosa; $1 \mu \mathrm{g}$ each) and BSA as control spotted on nitrocellulose membranes were incubated with CCN1 proteins (WT, D125A, or DM; $2 \mu$ g each in PBS) and bound CCN1 was visualized using anti-CCN1 antibodies. Dot blot shown is a representative image. $\mathbf{h}$ Senograms of SPR analysis of CCN1 binding to LPS. CCN1 at various concentrations was used as analyte to detect binding to LPS immobilized on HPA hydrophobic sensor chip. $K_{a}, K_{d}$ and $K_{D}$ values were obtained by kinetic analysis.

Colla1, did not show binding (Fig. 1d). Remarkably, whereas CCN1-WT and CCN1-D125A bound P. aeruginosa with similar dose-dependence, CCN1-DM was completely unable to bind, indicating that the essential binding site for $P$. aeruginosa was disrupted in CCN1-DM (Fig. 1e). Consistently, all deletion mutants lacking the CT domain tested $(\Delta \mathrm{CT}$, IGFBP-vWC, IGFBP) failed to bind P. aeruginosa (Fig. 1f). Mutations in CCN1DM changed several lysine residues and an arginine to glycines in the CT domain (Supplementary Fig. 1), rendering CCN1 unable to bind heparin, a polysaccharide of the glycosaminoglycan family ${ }^{35,36}$. Thus, we postulated that CCN1-DM may also be defective for binding lipopolysaccharides (LPS), a PAMP of
Gram-negative bacteria. Indeed, both CCN1-WT and CCN1D125A bound immobilized LPS from $P$. aeruginosa, but not CCN1-DM (Fig. 1g).

We further performed surface plasmon resonance (SPR) analysis to evaluate the binding of CCN1 to LPS, which was immobilized on an HPA hydrophobic sensor chip (Fig. 1h). Sensorgrams showed high-affinity CCN1 binding to LPS with a $K_{\mathrm{D}}$ of $67.4 \mathrm{nM}$. CCN1 also bound to the Gram-positive Streptococcus pneumoniae and the Gram-negative Salmonella typhimurium, supporting the notion that $\mathrm{CCN} 1$ may bind a broad spectrum of bacterial species through PAMPs (Supplementary Fig. 4). These results show that CCN1 is a PRR that can 
a
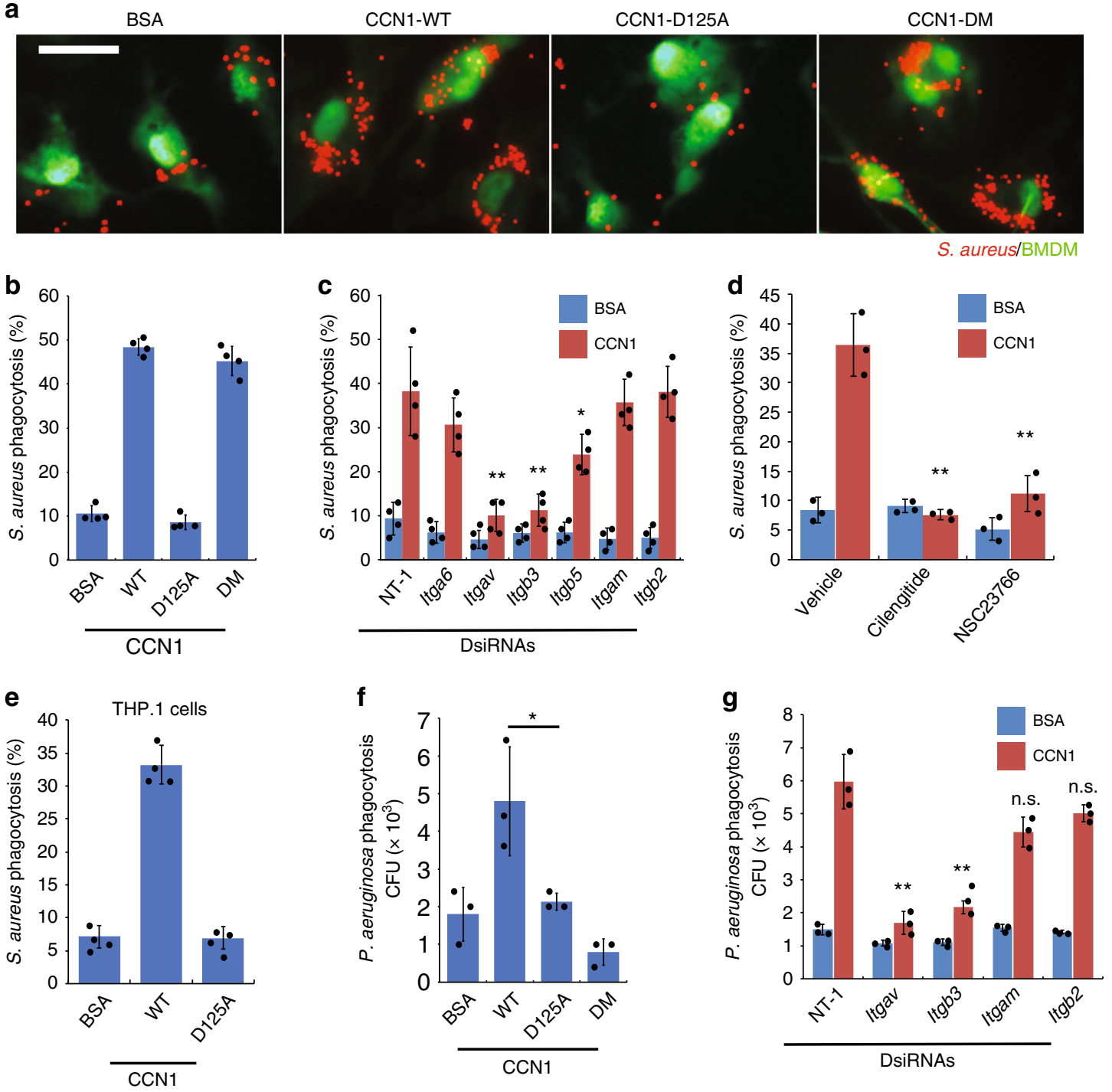

Fig. 2 CCN1 stimulates phagocytosis of bacteria through $\boldsymbol{\alpha}_{\mathbf{v}}$ integrins in macrophages. BMDMs (labeled with CellTracker ${ }^{T M} \mathrm{Green}$ ) were pretreated with either BSA, CCN1-WT, CCN1-D125A, or CCN1-DM proteins $(2 \mu \mathrm{g}$ per ml) followed by incubation with bacteria for 45 min. a Phagocytosis of S. aureus (pHrodo Red conjugates) is shown in representative images from fluorescence microscopy. Scale bar $=40 \mu \mathrm{m}$. $\mathbf{b}$ Quantification of phagocytosis of $S$. aureus by BMDMs pretreated with various proteins. c BMDMs were transfected with DsiRNAs to knockdown integrins $\alpha_{6}, \alpha_{v}, \beta_{3}, \beta_{5}$, $\alpha_{M}$, or $\beta_{2}$; knockdown efficiencies are shown in Supplementary Fig. 6. Cells were then pretreated with CCN1 or BSA, and phagocytosis of S. aureus was quantified. NT-1, nontargeting RNA. d Effect of cilengitide $(1 \mu \mathrm{M})$ and the Rac1 inhibitor NSC23766 (10 $\mu \mathrm{M})$ on CCN1-induced phagocytosis of S. aureus. e CCN1-induced phagocytosis in differentiated THP.1 human macrophages. $\mathbf{f}$ BMDMs were pretreated as above and then incubated with live $P$. aeruginosa (MOI of 10) for $45 \mathrm{~min}$, followed by gentamycin ( $200 \mu \mathrm{g}$ per $\mathrm{ml}$ for $15 \mathrm{~min}$ ) treatment. Phagocytosis was measured by enumeration of bacterial colonies grown from cell lysates. $\mathbf{g}$ Effects of DsiRNA-mediated knockdown of integrins $\alpha_{v}, \beta_{3}, \alpha_{M}$, or $\beta_{2}$ on CCN1-induced phagocytosis of $P$. aeruginosa. All data are expressed as mean \pm s.d. in triplicate determinations. Statistical evaluation was performed by one-sided, two-sample with equal variance $t$-tests. ${ }^{*} p<0.05$, ${ }^{\star *} p<0.01$, n.s. $=$ not significant. Source data are provided as a Source Data file.

directly recognize and bind bacterial PAMPs, including PGN in Gram-positive bacteria and LPS in Gram-negative bacteria.

CCN1 is an opsonin that stimulates phagocytosis of bacteria. Given the ability of CCN1 to bind bacterial PAMPs (Fig. 1) and to stimulate phagocytosis ${ }^{25}$, we hypothesized that $\mathrm{CCN} 1$ may act as an opsonin to stimulate bacterial clearance by phagocytosis. To test this possibility, we incubated bone marrow-derived macrophages (BMDMs; labeled green) with $S$. aureus bioparticles ( $\mathrm{pHrodo}{ }^{\circledR}$ conjugates, labeled red). Engulfment of $S$. aureus by macrophages was observed by fluorescence microscopy within $45 \mathrm{~min}$ (Fig. 2a). The addition of $\mathrm{CCN} 1$ protein stimulated engulfment by $\sim 5$-fold (Fig. 2a, b). Inhibition of actin polymerization with cytochalasin D abrogated bacterial uptake, confirming phagocytosis (Supplementary Fig. 5). The CCN1-D125A mutant protein failed to enhance phagocytosis, whereas CCN1$\mathrm{DM}$ was fully active (Fig. 2a, b), indicating that $\alpha_{v}$ integrins are the essential receptors for CCN1-induced phagocytosis. Consistently, dicer-substrate short interfering RNAs (DsiRNA)mediated knockdown of either integrin $\alpha_{\mathrm{v}}$ (Itgav) or $\beta_{3}$ (Itgb3) efficiently blocked CCN1-induced phagocytosis, whereas knockdown of $\alpha_{6}$ (Itga6), $\alpha_{M}$ (Itgam), or $\beta_{2}$ (Itgb2) did not (Fig. $2 c$ and Supplementary Fig. 6). Knockdown of integrin $\beta_{5}$ (Itgb5) only partially inhibited phagocytosis, suggesting that integrin $\alpha_{v} \beta_{3}$ is the primary phagocytic receptor, whereas $\alpha_{\mathrm{v}} \beta_{5}$ plays an auxiliary 
role. Thus, cilengitide, a cyclic-RGD peptide that selectively blocks integrins $\alpha_{v} \beta_{3} / \alpha_{v} \beta_{5}$, obliterated CCN1-induced phagocytosis (Fig. 2d). Likewise, CCN1-WT, but not CCN1-D125A, enhanced phagocytic uptake of $S$. aureus in bone marrow-derived neutrophils (BM-PMNs; Supplementary Fig. 7) and in differentiated THP.1 human macrophages (Fig. 2e), indicating the involvement of the same receptors in CCN1-induced phagocytosis of bacteria in neutrophils and human macrophages. Of note, integrin $\alpha_{M} \beta_{2}$ is also known as CR3 (CD11b/CD18), the type 3 complement receptor that binds iC $3 \mathrm{~b}$ to promote phagocytosis ${ }^{37}$, but is not involved in CCN1-induced phagocytosis based on these mutational (CCN1-DM) and DsiRNA knockdown results. Consistent with previous findings that $\alpha_{v} \beta_{3}$-mediated phagocytosis requires activation of Rac1 ${ }^{25,38}$, inhibition of Rac1 by NSC23766 blocked CCN1-induced phagocytosis (Fig. 2d). Concordant with the role of PI3K in Rac1-dependent cytoskeletal rearrangement ${ }^{39}$, PI3K inhibitor LY294002 reduced CCN1-induced phagocytosis ( 50\%), whereas ERK inhibitor (PD98059) or p38 MAPK inhibitor (SB203580) had no effect (Supplementary Fig. 5). Furthermore, commercially available CCN1 protein from different cellular sources also bound PGN and LPS and induced cilengitide-inhibitable phagocytosis of $S$. aureus (Supplementary Fig. 8), suggesting that these reproducible functions are bona fide activities of CCN1.

To evaluate whether $\mathrm{CCN} 1$ can also induce phagocytosis of Gram-negative bacteria, we tested its effects on $P$. aeruginosa (Fig. 2f, g). BMDMs were incubated with $P$. aeruginosa and phagocytosed bacteria were enumerated after extracellular bacteria were eliminated by gentamycin. We found that $\mathrm{CCN} 1$ also enhanced phagocytic uptake of $P$. aeruginosa, whereas CCN1-D125A was inactive (Fig. 2f). CCN1-DM, which was fully able to stimulate phagocytosis of $S$. aureus, was completely unable to enhance phagocytosis of $P$. aeruginosa (Fig. 2f). That CCN1DM was incapable of binding LPS or P. aeruginosa (Fig. 1e, g) provided a clear explanation for this finding and indicated that binding to bacteria through PAMP is critical for CCN1-induced bacterial clearance. Knockdown of either $\alpha_{v}$ or $\beta_{3}$ blocked CCN1induced phagocytosis of $P$. aeruginosa, whereas knockdown of $\alpha_{M}$ or $\beta_{2}$ had little effect (Fig. 1g). These results show that CCN1 opsonizes both Gram-positive and Gram-negative bacteria for phagocytosis, engaging integrin $\alpha_{v} \beta_{3}$ as the primary phagocytic receptor.

CCN1 increases ROS for bacterial killing after phagocytosis. Upon phagocytosis, ingested bacteria are trapped in vacuoles, or phagosomes, which undergo maturation to become phagolysosomes with diverse antimicrobial arsenals, including microbicidal peptides, lipases, and capacity to generate reactive oxygen species $(\mathrm{ROS})^{40}$. CCN1 is known to induce ROS production in other biological contexts ${ }^{26,41}$, prompting us to test whether CCN1 can facilitate bacterial killing following phagocytosis by inducing ROS. To monitor bacterial killing, we allowed BMDM phagocytosis of S. aureus to proceed for $90 \mathrm{~min}$ and eliminated the remaining extracellular bacteria by lysostaphin ${ }^{42}$. BMDMs were then treated with $\mathrm{CCN} 1$ and the number of surviving intracellular bacteria was monitored over time. As shown in Fig. 3a, the viable S. aureus count in CCN1-treated BMDMs was significantly lower than that of bovine serum albumin (BSA)-treated control after a $3 \mathrm{~h}$ chase period, indicating that $\mathrm{CCN} 1$ accelerated bacterial killing after phagocytosis.

Next, we examined whether CCN1 stimulated ROS production to enhance bacterial killing. Treatment of BMDMs with CCN1induced ROS production within $30 \mathrm{~min}$ as judged by staining with dihydroethidium (DHE), a superoxide $\left(\mathrm{O}_{2}{ }^{-}\right)$detection dye (Fig. 3b, c). CCN1-DM also induced ROS production but not
CCN1-D125A, indicating that CCN1 acts through $\alpha_{\mathrm{v}}$ integrins (Fig. 3b, c). Accordingly, cilengitide effectively abolished CCN1induced ROS and subsequent bacterial killing (Fig. $3 \mathrm{~d}$, e). In macrophages, NADPH oxidase 2 (NOX2) is the principal enzyme responsible for superoxide production ${ }^{43}$. Whereas Racl is an activating subunit of NOX2 in macrophages, Rac2 activates NOX2 in neutrophils ${ }^{44,45}$. Consistently, the Rac1 inhibitor NSC23766 blocked CCN1-induced ROS production and bacterial killing (Fig. 3f, g). Apocynin, a non-isoform-specific NOX inhibitor and a ROS scavenger, exhibited strong inhibitory effects (Fig. 3f, g). The NOX2 inhibitor (GSK2795039), but not NOX1 inhibitor (ML-171), diminished CCN1-induced ROS production and bacterial killing (Fig. 3f, g). These results show that CCN1 enhances microbial killing after phagocytosis by the induction of ROS through integrin $a_{\mathrm{v}}$-mediated activation of Rac1-NOX2.

CCN1 is critical for bacterial clearance in animal models. Given that CCN1 opsonizes bacteria for phagocytosis and killing, we investigated the role of CCN1 in host defense against bacterial infections in animal models. Since professional phagocytes are derived from the myeloid lineage, we generated mice with $\mathrm{Ccn} 1$ deleted specifically in myeloid cells by crossing $C c_{n} 1^{f l o x} / f l o x$ mice with the deleter strain $L y s M$-Cre, vielding Con $1^{\text {flox/flox; }}$ Lys $M$-Cre mice (hereafter called $C c n 1^{\Delta M y e l o i d}$ mice; Supplementary Fig. 9). $C c n 1$ expression in $C c n 1^{\Delta M y e l o i d}$ mice was greatly reduced in peritoneal macrophages, BMDMs, and BM-PMNs, but remained at WT levels in splenic B and T lymphocytes (Fig. 4a), indicating Ccn1 deletion specifically in myeloid cells.

$S$. aureus is a leading cause of lethal bacteremia ${ }^{46,47}$. To examine the functions of CCN1 in bacteremia, Con $1_{\text {flox/flox }}$ (control) and $C_{c n} 1^{\Delta \text { Myeloid }}$ mice were infected intravenously (i.v.) with S. aureus $\left(7.5 \times 10^{8} \mathrm{CFU}\right.$ per mouse; Fig. $\left.4 \mathrm{~b}\right)$. Remarkably, Ccn $1^{\Delta \text { Myeloid }}$ mice exhibited $100 \%$ mortality within 5 days, whereas $60 \%$ of $C c n 1^{f l o x} f f l o x$ mice survived at least 10 days (Fig. 4b), showing that myeloid expression of $C c n 1$ strongly protects against $S$. aureus bacteremia. Bloodstream infection of $S$. aureus often disseminates to multiple internal organs, including the liver, kidney, and heart ${ }^{48}$. To examine tissue colonization of disseminated bacteria, we used a reduced dose of $S$. aureus $(2 \times$ $10^{8} \mathrm{CFU}$ per mouse; i.v.) to minimize mortality (Fig. $4 \mathrm{c}, \mathrm{d}$ ). The liver and kidney of $C_{c n} 1^{\Delta \text { Myeloid }}$ mice displayed higher bacterial burdens ( $\sim 5$-fold) compared to $C c n 1^{\text {floxflox }}$ mice 5 days post infection (Fig. 4c), as confirmed by H\&E staining and immunohistochemistry (Fig. 4d). Both liver and kidney sections from $C c n 1^{\Delta M y e l o i d}$ mice displayed multiple nidi that are surrounded by pseudo-capsules and massive infiltration of neutrophils, characteristics of S. aureus pyogenic abscesses (Fig. 4d), which were not observed in Ccn $1^{f l o x}$ flox mice. Bacterial colonization was also much more severe in the $C c n 1^{\Delta M y e l o i d}$ heart, with $~ 100$-fold more bacterial burden compared to controls (Fig. 4c).

As $S$. aureus is the most prominent cause of $\mathrm{SSTI}^{49}$, we also examined blood dissemination in a skin infection model. After a bolus of $S$. aureus $\left(4 \times 10^{6}\right.$ CFU per mouse) was injected subcutaneously into mouse flank skin, blood dissemination was $\sim 2$ orders of magnitude higher in $C c n 1^{\Delta \text { Myeloid }}$ mice than controls 1 day post infection, and remained high 2 days post infection while bacterial counts in $C c n 1^{f l o x} / f l o x$ mice approached zero (Fig. 4e). Similarly, $C c n 1^{\Delta M y e l o i d}$ mice infected with P. aeruginosa showed increased mortality in bacteremia (i.v. infection) and sustained blood dissemination in peritonitis (i.p. infection), indicating that $\mathrm{CCN} 1$ also defends against infection by Gramnegative bacteria (Supplementary Fig. 10). These results show that Ccn1 expression in myeloid cells, including macrophages and neutrophils, plays a crucial role in bacterial clearance in mouse models of infection. 
a

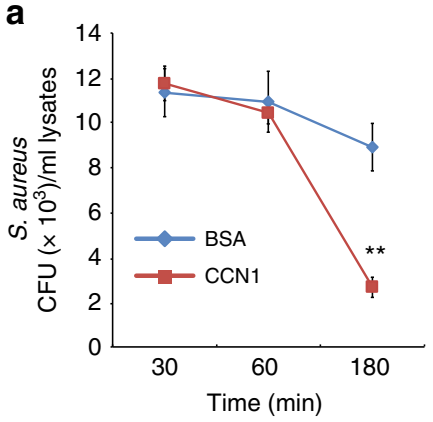

b

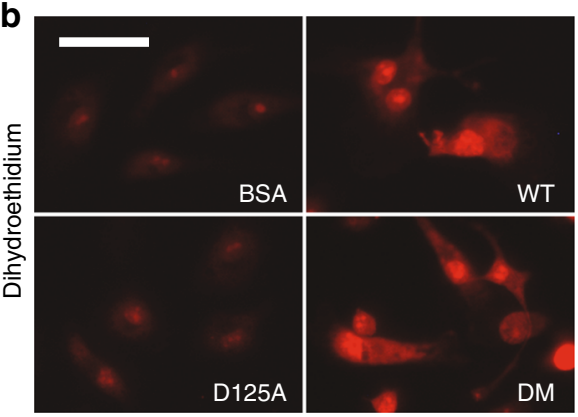

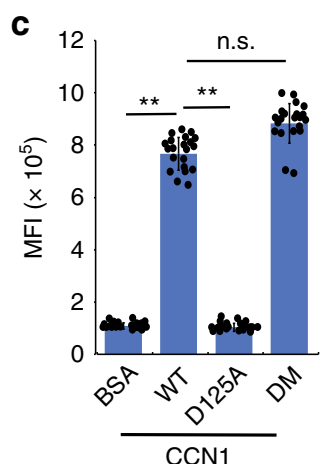
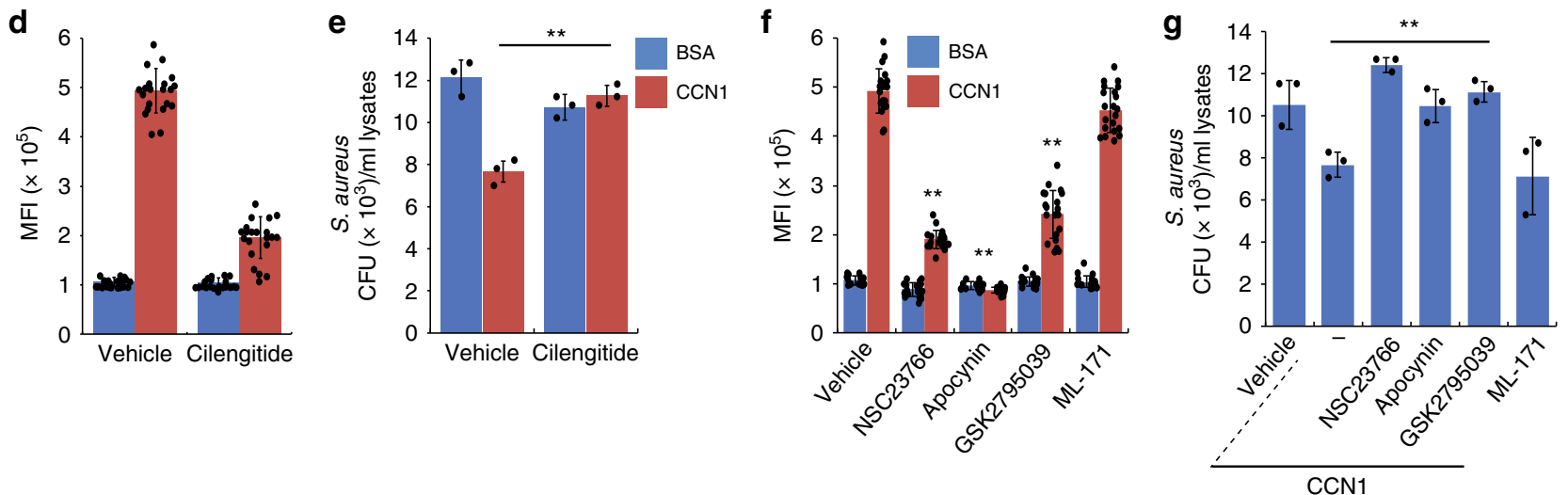

Fig. 3 CCN1 enhances bacterial killing after phagocytosis through ROS production. a Lysostaphin protection assay for assessing S. aureus killing after phagocytosis. After BMDMs phagocytosed S. aureus and extracellular bacteria were eliminated by lysostaphin, cells were treated with CCN1 or BSA ( $2 \mu \mathrm{g}$ per $\mathrm{ml}$ each) and viable bacteria inside BMDMs were enumerated at indicated chase periods. b Superoxide $\left(\mathrm{O}_{2}{ }^{-}\right.$) was measured by dihydroethidium (DHE, $5 \mu \mathrm{M}$ ) staining in BMDMs treated with recombinant CCN1 proteins (WT, D125A, or DM; $2 \mu$ g per ml each) for 30 min. Representative images shown were acquired from fluorescence microscopy. Bar $=40 \mu \mathrm{m}$. c High-magnification images were taken from at least ten random fields and mean fluorescence intensity (MFI) was calculated using Image J software. d ROS production was quantified as MFI using DHE fluorescence in BMDMs pretreated with cilengitide $(1 \mu \mathrm{M})$, followed by CCN1 or BSA ( $2 \mu \mathrm{g}$ per $\mathrm{ml}$ each). e $\mathrm{S}$. aureus killing assays were performed as in a with cilengitide pretreatment. $\mathbf{f}$ The effects of various inhibitors on CCN1-induced ROS production. All inhibitors were added 30 min prior to CCN1 treatment. Rac1 inhibitor NSC23766 (10 $\mu$ M); NOX inhibitor Apocynin (10 $\mu$ M); NOX2 inhibitor GSK2795039 (10 $\mu \mathrm{M})$; NOX1 inhibitor ML-171 (10 $\mu \mathrm{M})$. $\mathbf{g}$ Effects of various inhibitors on bacterial killing using lysostaphin protection assays as above. All data were acquired from at least three independent assays and are expressed as mean \pm s.d. in triplicate determinations. Statistical evaluation was performed by one-sided, two-sample with equal variance $t$-tests. ${ }^{\star \star} p<0.01$, n.s. $=$ not significant. Source data are provided as a Source Data file.

CCN1 drives host defense through its $\alpha_{\mathrm{v}}$ integrin-binding site. To assess the role of $\alpha_{v}$ integrins-mediated CCN1 phagocytic and bactericidal functions in bacterial clearance in vivo, we examined knock-in mice in which the $C c n 1$ genomic locus is replaced by alleles encoding either CCN1-D125A $\left(C c n 1^{D 125 A / D 125 A} \text { mice }\right)^{25}$ or CCN1-DM $\left(C c n 1^{D M / D M} \text { mice }\right)^{26}$. Upon i.v. infection with $S$. aureus ( $7.5 \times 10^{8} \mathrm{CFU}$ per mouse), $90 \%$ of $C c n 1^{D 125 A / D 125 A}$ mice perished by day 8 post infection, compared to $\sim 20 \%$ mortality in either $C c n 1^{W T / W T}$ or $C c n 1^{D M / D M}$ mice (Fig. 5a). These results indicate that CCN1 functions mediated through $\alpha_{v}$ integrins, including induction of phagocytosis and ROS-dependent killing, are critical for bacterial defense in vivo. Assessment of tissue dissemination upon $S$. aureus infection $\left(2 \times 10^{8}\right.$ CFU per mouse; i.v.) showed significantly higher levels of bacterial load in the kidney and heart from $C c n 1^{D 125 A / D 125 A}$ mice 5 days post infection (Fig. 5b). Interestingly, robust $S$. aureus colonization was accompanied by extensive tissue damage and loss of glomerular structures in the kidney cortex from Ccn1 $125 \mathrm{~A} / \mathrm{D} 125 \mathrm{~A}$ mice, suggesting that integrin $\alpha_{\mathrm{v}}$-mediated CCN1 functions may play additional roles in parenchymal injury repair (Fig. 5c).

Exogenous CCN1 accelerates bacterial clearance. Given the strong protective role of $\mathrm{CCN} 1$ against bacterial infections, we tested whether administration of exogenous $\mathrm{CCN} 1$ protein may accelerate bacterial clearance in infected mice. Mice were infected with $S$. aureus $\left(5 \times 10^{7} \mathrm{CFU}\right.$ per mouse, i.p.) for $1 \mathrm{~h}$, followed by CCN1 protein injection. Blood dissemination of $S$. aureus was observed at $3 \mathrm{~h}$ post infection in both $C c n 1^{W T / W T}$ and Ccn $1^{\text {flox/flox }}$ mice and was largely eliminated by $10 \mathrm{~h}$ (Fig. $5 \mathrm{~d}, \mathrm{e}$ ). By contrast, high levels of $S$. aureus in blood were sustained even after $10 \mathrm{~h}$ in both $C \mathrm{cn} 1^{\mathrm{D} 125 \mathrm{~A} / \mathrm{D} 125 \mathrm{~A}}$ and $C \mathrm{cn} 1^{\Delta \text { Myeloid }}$ mice (Fig. $5 \mathrm{~d}, \mathrm{e})$. Injection of CCN1 (5 $\mu \mathrm{g}$ per mouse, i.p.) greatly reduced $S$. aureus blood dissemination, virtually eliminating bacterial counts as early as $3 \mathrm{~h}$ post infection in both genotypes (Fig. 5d, e). These results suggest that administration of exogenous CCN1 may have therapeutic value in the treatment of antibiotic-resistant bacterial infections.

CCN1 binds and activates TLR2 and TLR4. Macrophages respond to the presence of microbes by engulfment of the invaders and production of cytokines and chemokines, which marshal the infiltration of neutrophils and other immune cells for both innate and adaptive immune defense ${ }^{12}$. Therefore, we examined whether CCN1 may also contribute to host defense through regulating the inflammatory response. We induced acute peritonitis in mice with i.p. infection of $S$. aureus $\left(5 \times 10^{7} \mathrm{CFU}\right.$ per mouse $)$ and measured the levels of inflammatory cytokines and chemokines in peritoneal lavage. Upon infection, both cytokines (TNFa and IL6) and 

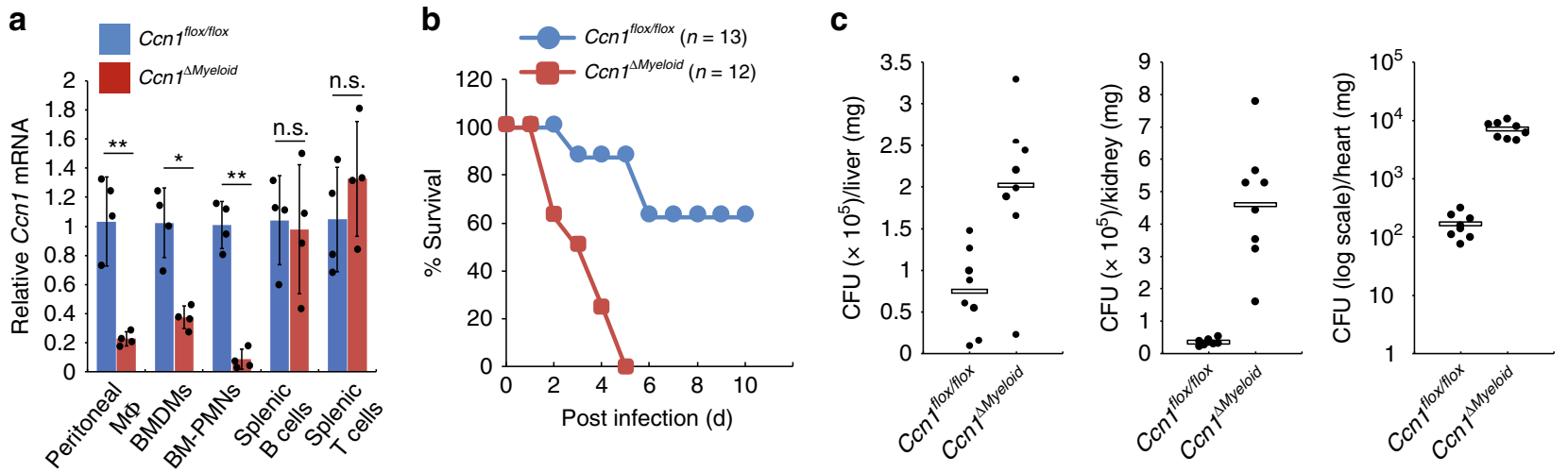

d
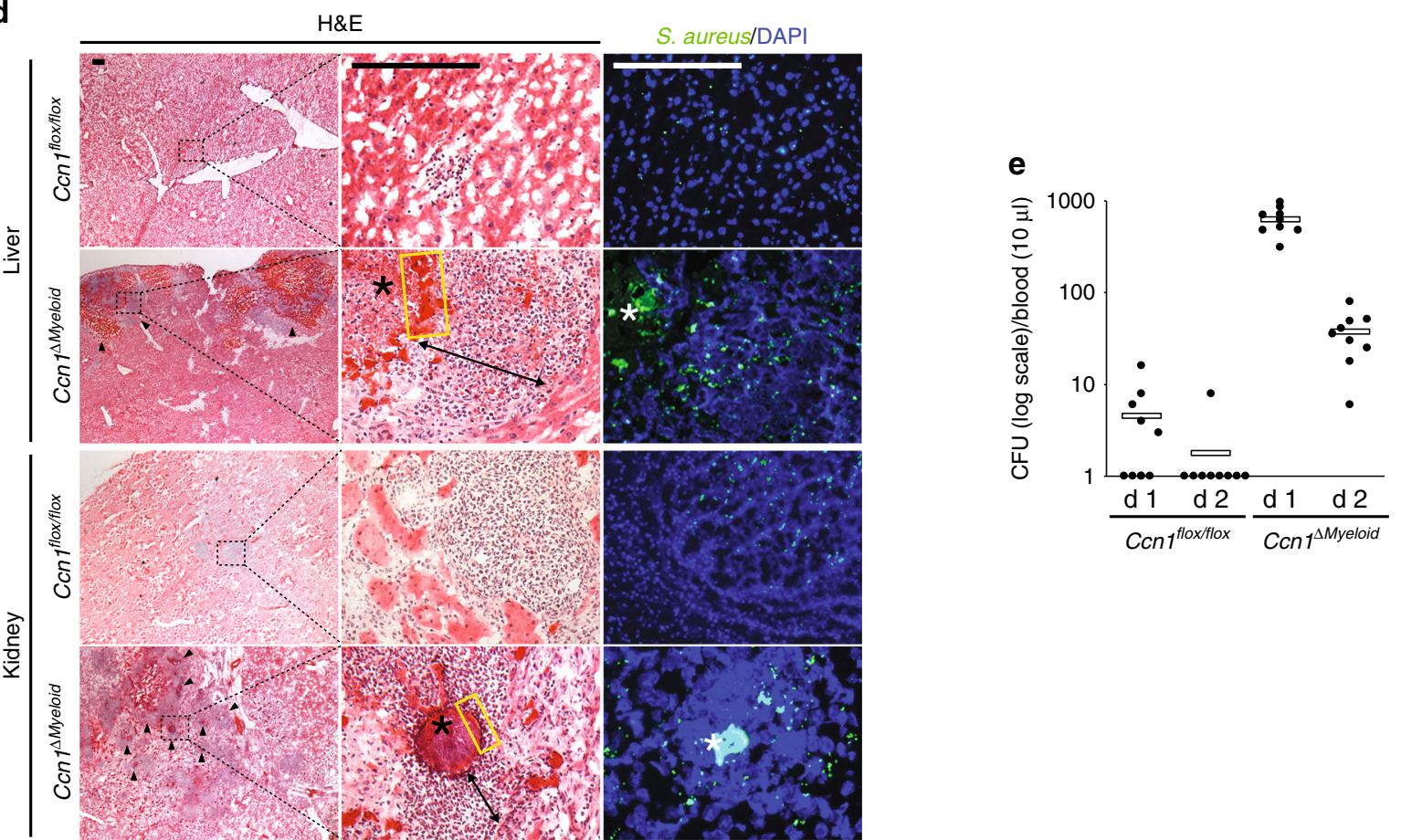

Fig. 4 Ccn1 expression in myeloid cells is critical for host defense against S. aureus infections. a Ccn1 mRNA in peritoneal macrophages (M $\Phi$ ), BMDMs and PMNs, and splenic $B$ and T cells from $C \mathrm{cn}$ flox/flox and $\mathrm{Ccn}{ }^{\Delta \text { Myeloid }}$ mice was analyzed using qRT-PCR. Myeloid-specific deletion was confirmed using splenic B and T cells as controls. Data are represented as mean \pm s.d. from triplicate experiments. Statistical evaluation was performed by one-sided, two-

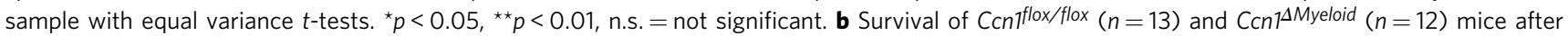
infection with S. aureus $\left(7.5 \times 10^{8} \mathrm{CFU}\right.$ per mouse, i.v.). c Tissue colonization of S. aureus in Ccnflox/flox and Ccn $1 \Delta$ Myeloid mice infected with S. aureus $\left(2 \times 10^{8}\right.$ CFU per mouse, i.v.). Bacterial counts in liver, kidney, and heart ( $n=8$ each) 5 days post infection were evaluated by growth of serially diluted tissue homogenates on tryptic soy agar with $5 \%$ sheep blood and plotted as CFU per mg tissues. $\mathbf{d}$ Histological examination of liver and kidney of Ccnfflox/flox and

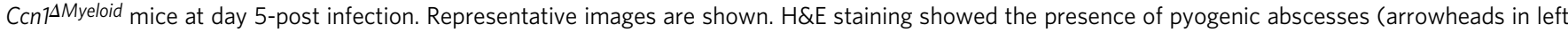
panels) in both liver and kidney from $C \mathrm{cn} 7^{4 M}$ Myeloid mice, whereas no pyogenic abscesses were found in $C \mathrm{cn} 7^{\text {flox/flox }}$ mice. Boxed regions with dotted line are expanded in high magnification in middle panels. Asterisk $\left(^{\star}\right)$ points to nidus, yellow rectangular box indicates pseudo-capsule, and bidirectional arrow shows regions of neutrophils. S. aureus colonization was visualized in adjacent sections using anti-S. aureus antibodies (green, Alexafluor488-anti-rabbit IgG) in immunofluorescence staining (right panels). DAPI (blue) was used as a counterstaining. Scale bar $=100 \mu \mathrm{m}$. e Blood dissemination of $S$. aureus was determined at indicated days after subcutaneous infection of S. aureus $\left(5 \times 10^{5} \mathrm{CFU}\right.$ in $\left.50 \mu \mathrm{lPBS}\right)$ in Ccn $7^{\text {flox }} /$ flox and $\mathrm{Ccn} 7^{\Delta M y e l o i d}$ mice $(n=9$ each). Blood $(10 \mu \mathrm{l})$ was plated for colony quantification. Source data are provided as a Source Data file.

chemokines (KC and MCP1) levels were significantly increased in Con $1^{\text {flox/flox }}$ mice, whereas this inflammatory response was greatly reduced in $C c n 1^{\Delta \text { Myeloid }}$ mice (Fig. 6a-d). Consistent with decreased KC chemokine levels (Fig. 6c), complete blood count (CBC) analysis found fewer circulating neutrophils in $C \mathrm{cn} 1^{\Delta \text { Myeloid }}$ mice following infection (Fig. 6e). These results show that Ccn1 expressed in myeloid cells plays a key role in the inflammatory response to bacterial infections.

To determine how CCN1 may contribute to the inflammatory response, we tested whether $\mathrm{CCN1}$ can by itself induce inflammation without infection. When i.p. injected into uninfected C56BL/6J (B6) mice, both CCN1-WT and the CCN1D125A mutant elevated the levels of cytokines (TNFa and IL6) in peritoneal exudates and increased neutrophils in circulating blood (Supplementary Fig. 11). These results suggest that CCN1 itself, in the absence of infection, can induce sterile inflammation independent of its binding to integrin $\alpha_{v} \beta_{3}$ and activities downstream of integrin signaling.

Sterile inflammation is often induced through TLRs recognizing DAMPs, which signal tissue damage ${ }^{17,18}$. Thus, we tested the 

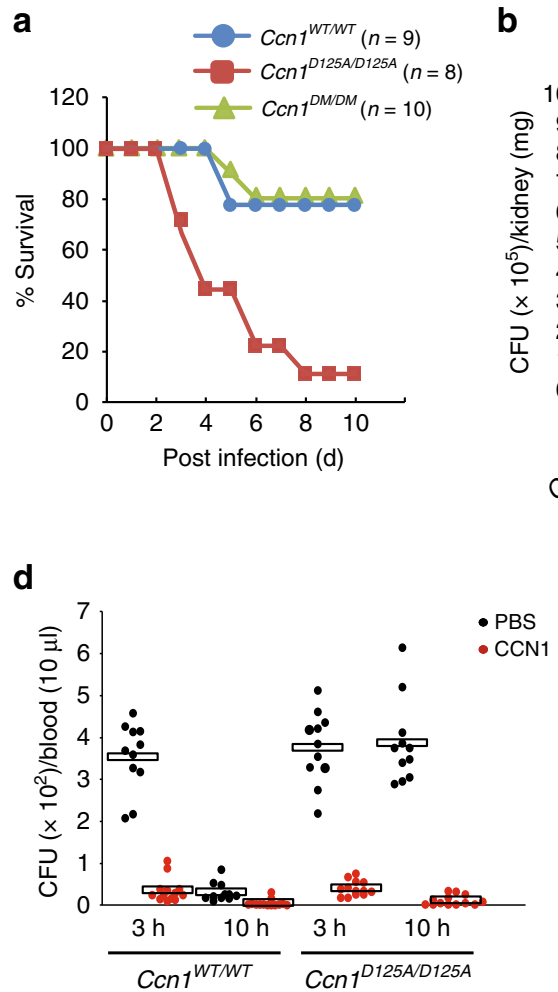

b

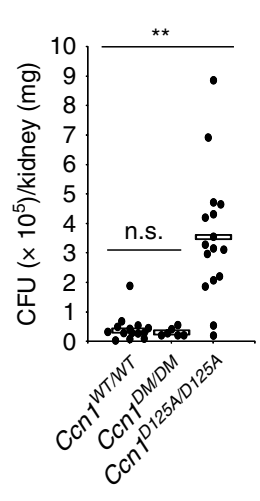

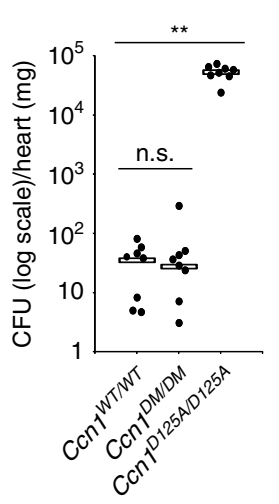

c H\&E

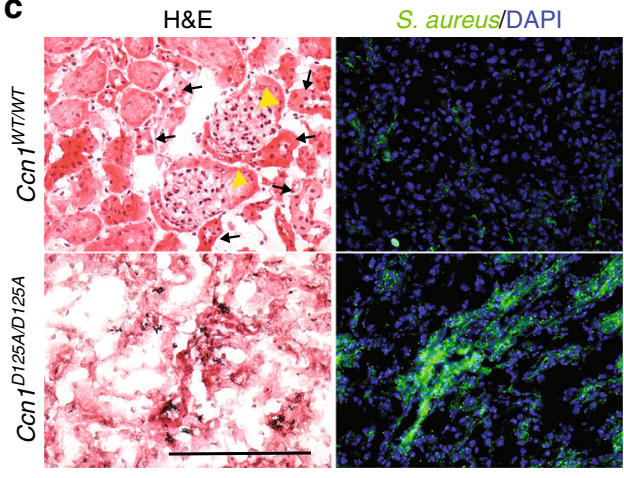

e

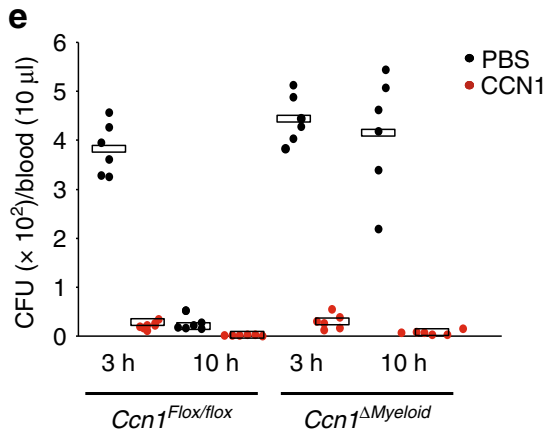

Fig. 5 CCN1 functions mediated through its integrin $\boldsymbol{\alpha}_{\mathbf{v}}$-binding site are crucial for host defense. a Survival was monitored in mice infected with $S$. aureus $\left(7.5 \times 10^{8}\right.$ CFU per mouse, i.v.). Ccn1WT/WT $n=9 ; C_{c n 1 D 125 A / D 125 A}, n=8 ; C c n 1$ DM/DM,$n=10$. b Colonization in the kidney and heart was evaluated in mice infected with S. aureus $\left(2.5 \times 10^{8} \mathrm{CFU}\right.$ per mouse, i.v. $)$. Bacterial loads were enumerated by serial dilution of tissue homogenates at day 5 -post infection in $C c n 1$ WT/WT ( $n=16$ for kidney, $n=8$ for heart), $C c n 1 D 125 A / D 125 A$ ( $n=16$ for kidney, $n=8$ for heart), and Ccn1DM/DM ( $n=6$ for kidney, $n=8$ for heart) mice. Statistical evaluation was performed by one-sided, two-sample with equal variance $t$-tests. ${ }^{\star \star} p<0.01$; n.s. $=$ not significant. c Histological evaluation of the kidney cortex after S. aureus infection. Kidney sections from Ccn1WT/WT and Ccn1D125A/D125A mice at day 5-post infection were stained with H\&E. Glomeruli (yellow arrowheads) and tubules (black arrows) are intact in Ccn1WT/WT mice, but severely damaged in Ccn1D125A/D125A mice. Adjacent sections were visualized in immunofluorescence staining with polyclonal anti-S. aureus antibody (green) and counterstained with DAPI (blue). Scale bar $=100 \mu$ m. d Treatment of mice with CCN1 protein accelerated bacterial clearance. Ccn1WT/WT and Ccn1D125A/D125A mice ( $n=11$ per group per genotype) were challenged with acute peritonitis by infection of S. aureus $\left(2 \times 10^{7} \mathrm{CFU}\right.$ per mouse, i.p.), followed by i.p. injection of CCN1 protein ( $\mu \mu$ ger mouse) or PBS $1 \mathrm{~h}$-post infection. Total blood was drawn at indicated times and $10 \mu \mathrm{l}$ was plated for colony enumeration. e $C \mathrm{cn} 7^{f l o x} /$ flox and $C \mathrm{cn} 7 \mathrm{Myeloid}$ mice $(n=6$ per group per genotype) were infected with S. aureus and bacterial clearance with or without CCN1 treatment was evaluated as above. Source data are provided as a Source Data file.

possibility that CCN1 may directly regulate inflammation through TLRs using mice that lack MyD88 $\left(\mathrm{Myd}^{-8^{-/}}\right)$, a cytoplasmic adaptor molecule that is essential for the signaling of most $\mathrm{TLRs}^{50}$. Remarkably, whereas i.p. injected CCN1 elevated the levels of both cytokines (TNFa and IL6) and chemokines (KC and MCP1) in the peritoneal lavage of $B 6$ mice, it failed to do so in $M y d 88^{-/-}$mice (Fig. 7a-d). Consistently, CBC analysis showed no increase in blood neutrophils in $M y d 88^{-/-}$mice upon CCN1 injection (Fig. 7e). These results indicate that CCN1induced inflammatory response in vivo is mediated through a MyD88-dependent mechanism, possibly via TLR signaling. To assess the function of CCN1 in an isolated cell system, we treated BMDMs from $B 6$ and $M y d 88^{-/-}$mice with CCN1. CCN1 elevated both Tnfa and Il6 mRNAs in B6 BMDMs to levels similar to those induced by PGN, but this induction did not occur in BMDMs from $M y d 88^{-/-}$mice (Fig. 7f). As expected, induction of Tnfa and Il6 expression by PGN and LPS was completely obliterated in $M y d 88^{-/}$BMDMs, since these PAMPs are known to induce inflammatory genes through TLRs (Fig. 7f). Likewise, $\mathrm{CCN} 1$ also induced inflammatory gene expression in differentiated THP.1 human macrophages (Supplementary Fig. 12).

The possibility that CCN1 can activate TLR signaling suggests that it may physically interact with TLRs, among which TLR2 and
TLR4 are principal receptors for bacterial PAMPs and DAMPs ${ }^{18,51}$. Remarkably, we found that both human recombinant TLR2 and TLR4 proteins, which do not contain MD2, efficiently bound immobilized CCN1 in a dose-dependent manner in a solid-phase-binding assay (Fig. 8a). CD14, an LPS transport protein, failed to show binding as a negative control, indicating specificity of the assay.

To further confirm the binding of CCN1 to TLR2 and TLR4 and to assess binding affinity, we performed SPR analysis (Fig. 8b, c and Supplementary Fig. 13). Sensorgrams showed CCN1 interacted specifically with TLR2 and TLR4 immobilized on CM5 sensor chip with $K_{\mathrm{D}}$ values of $227 \mathrm{nM}$ and $291 \mathrm{nM}$, respectively. In addition, $\mathrm{SPR}$ analysis also confirmed specific interaction between CCN1 and its phagocytic receptor, integrin $\alpha_{v} \beta_{3}$, with a $K_{\mathrm{D}}$ of $202 \mathrm{nM}$ (Supplementary Fig. 13). These results clearly show that CCN1 binds TLR2 and TLR4 directly with affinities similar to its binding to the phagocytic receptor integrin $\alpha_{v} \beta_{3}$.

Further analysis by immunoblotting showed that CCN1-WT and CCN1-D125A bound to both TLR2 and TLR4, whereas CCN1-DM only bound TLR4 but not TLR2 (Fig. 8d). These findings indicate that the DM mutations disrupted the CCN1binding site for TLR2. Consistent with this binding pattern, 
a

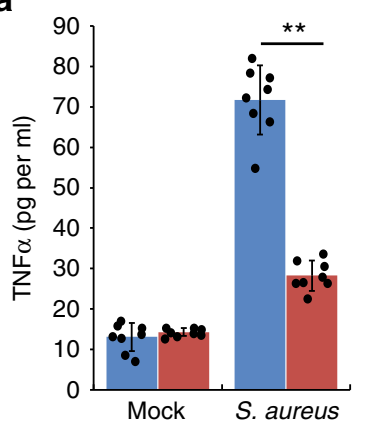

C

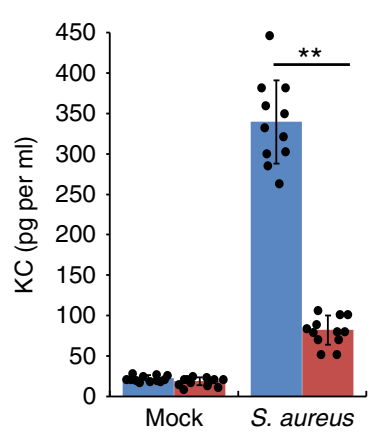

b

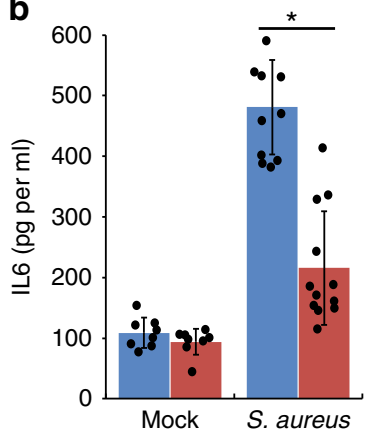

d

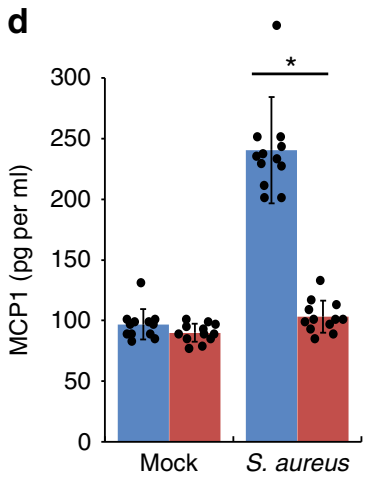

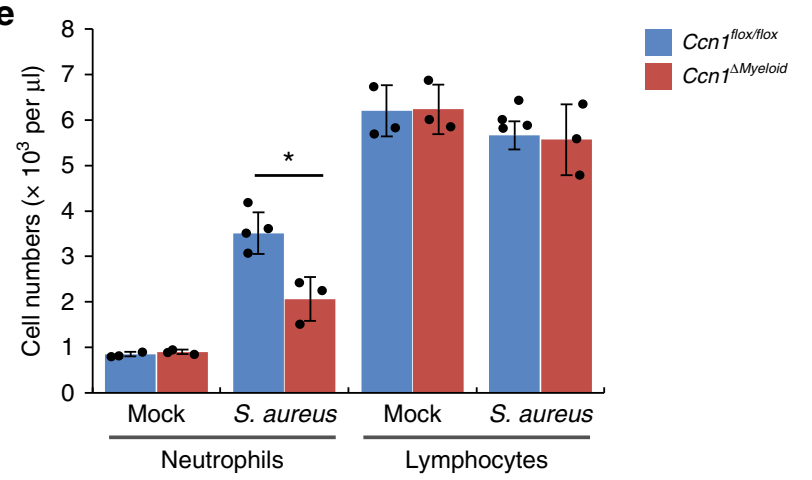

Fig. 6 CCN1 is critical for the host inflammatory response upon bacterial

infection. a-d Quantification of cytokines and chemokines in the peritoneum in $\mathrm{C}$ cnfflox/flox or $\mathrm{C}_{\mathrm{c} n}{ }^{\Delta \text { Myeloid }}$ mice ( $n=6$ per group per genotype) infected with $S$. aureus $\left(2 \times 10^{7} \mathrm{CFU}\right.$ per mouse i.p.). Peritoneal exudates were analyzed by ELISA to quantify the levels of TNF $\alpha$ (a) at 30 min and IL6 (b), KC (c), and MCP1 (d) at $2 \mathrm{~h}$ post infection. e Neutrophils and lymphocytes contents in blood drawn at $2 \mathrm{~h}$ post infection were determined using Advia 120 analyzer. All data are represented as mean \pm s.d. acquired in triplicate determinations. Statistical evaluation was performed by one-sided, two-sample with equal variance $t$ tests. ${ }^{\star} p<0.05,{ }^{\star \star} p<0.01$. Source data are provided as a Source Data file.

CCN1-WT and CCN1-D125A induced a higher level of inflammatory gene expression in B6 BMDMs compared to CCN1-DM, which only bound TLR4 but not TLR2 (Fig. 8e). Induction of Tnfa and Il $\mathrm{l}$ was abolished in BMDMs from

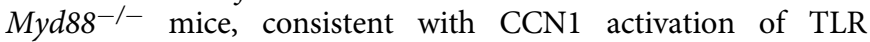
signaling (Fig. 8e). To further confirm that $\mathrm{CCN1}$ activates gene expression through direct binding to TLRs, we examined the effects of CCN1 in BMDMs from knockout mice deficient in TLR2 or TLR4. Induction of Tnfa and Il6 by CCN1-WT and CCN1-D125A was reduced in BMDMs of either $\mathrm{Tlr}^{-/-}$or Tlr4 $4^{-1}$ mice, indicating that $\mathrm{CCN} 1$ activates gene expression through both TLR2 and TLR4 (Fig. 8f). However, CCN1-DMinduced gene expression was eliminated only in $\mathrm{Tlr}^{-/-}$BMDMs but unchanged in Tlr2 ${ }^{-/}$BMDMs (Fig. 8f), consistent with the selective binding of CCN1-DM to TLR4 but not TLR2 (Fig. 8d). Altogether, these results show that $\mathrm{CCN} 1$ can directly bind and activate TLR2 and TLR4 and may function as a DAMP to regulate inflammatory responses, independent of bacterial infections.

\section{Discussion}

In a hostile environment replete with numerous and disparate microbial invaders, animal hosts have developed multiple arsenals for self-defense. Opsonins are structurally diverse frontline defense molecules that recognize and bind bacteria to mark them for phagocytosis and elimination through specific cell surface receptors $^{52}$. Families of opsonins include antibodies, complement proteins, and factors such as pentraxins (serum amyloid P and Creactive protein $)^{53,54}$, collectins $s^{55}$, and ficolins ${ }^{56}$. As each opsonin may have idiosyncratic target specificities and efficacy, the nature and availability of specific opsonins at the sites of infection may affect the pathological outcome. Here, we show that the matricellular protein CCN1 is an opsonin for both Gram-positive and Gram-negative bacteria, including S. aureus (MRSA) and P. aeruginosa and promotes their removal by phagocytosis and ROSmediated killing (Fig. 9). Ccn1 is essential for efficient bacterial clearance in mouse models of infection, and administration of CCN1 protein markedly accelerates bacterial clearance. As the emergence of antibiotic-resistant bacteria is a critical public health issue $^{2,3}$, the efficacy of CCN1 against these common antibioticresistant pathogens suggests potential therapeutic value.

Our current study was predicated on the discovery that $\mathrm{CCN} 1$ acts as a bridging molecule for efferocytosis of apoptotic neutrophils ${ }^{25}$. However, most bridging molecules for efferocytosis are incapable of opsonizing bacteria, an activity that requires specific recognition of bacterial PAMPs ${ }^{57}$. The binding of CCN1 to PGN of $S$. aureus is mediated through both the vWC and TSR domains (Fig. 1c, g and Supplementary Fig. 3). Although thrombospondin1 (TSP-1) has been shown to bind $\mathrm{PGN}^{58}$, whether this binding occurs through the TSR domain of TSP-1 is unknown. The TSR of mindin binds LPS and LTA ${ }^{59}$, whereas TSR of BAIl binds only LPS $^{60}$. In CCN1 the TSR binds PGN but not LPS (Supplementary Fig. 3), underscoring the functional diversity of various TSR domains. By contrast, CCN1 recognition of LPS is dependent on a cluster of positively charged residues in the CT domain (Fig. 1g) ${ }^{35}$. CCN1 can also bind other bacteria, including the Gram-positive S. pneumoniae and the intracellular Gram-negative S. typhimurium (Supplementary Fig. 4), indicating that CCN1 may potentially opsonize a broad spectrum of bacterial species.

Phagocytosis is a well-coordinated process involving target recognition and tethering, followed by engulfment of the cargo to form an intracellular membrane-enclosed phagosome ${ }^{61}$. CCN1 engages integrin $\alpha_{v} \beta_{3}$ as the phagocytic receptor, leading to the activation of the small GTPase Racl (Fig. 2), which is known to regulate actin cytoskeleton reorganization, cell motility, and phagocytic cup formation ${ }^{62,63}$. We have previously shown that in efferocytosis CCN1 activates Rac1 in macrophages upon engagement of integrin $\alpha_{\mathrm{v}} \beta_{3}$, leading to formation of the integrinp130Cas/CrkII complex ${ }^{25}$. This complex recruits DOCK180, a Racl-activating guanine nucleotide exchange factor (GEF), thereby activating Rac1 ${ }^{64,65}$. Thus, $\mathrm{CCN} 1$ engagement of integrin $\alpha_{\mathrm{v}} \beta_{3}$ and activation of Racl play crucial roles in the phagocytosis of both apoptotic cells and bacterial pathogens. Indeed, CCN1induced Racl activation not only regulates phagocytic engulfment of bacteria but is also critical for NOX2-dependent ROS generation to eliminate ingested bacteria (Figs. 2 and 3), thereby parsimoniously coupling these two molecularly distinct but functionally connected events. 

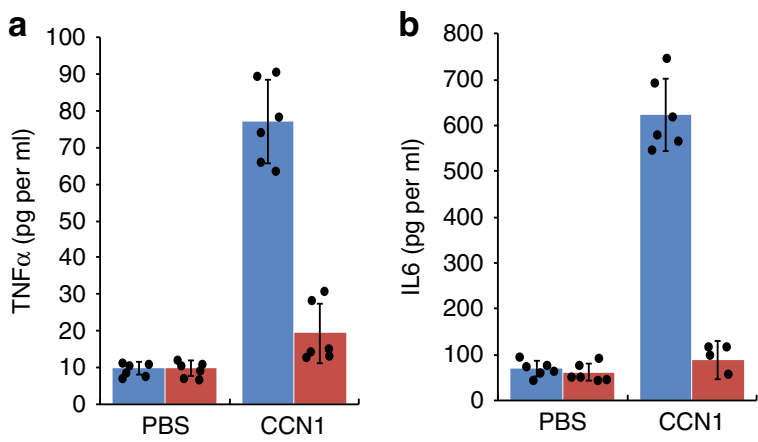

e

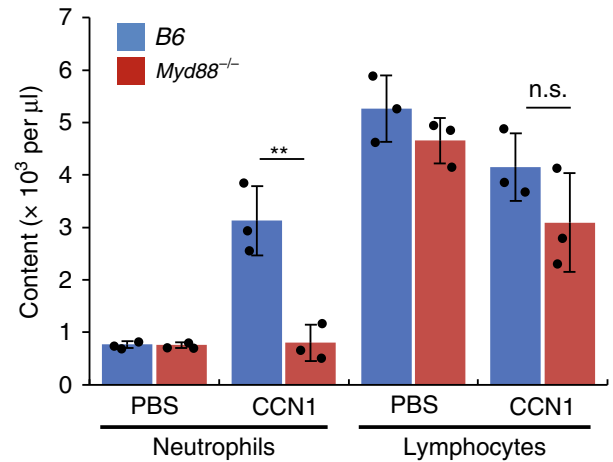

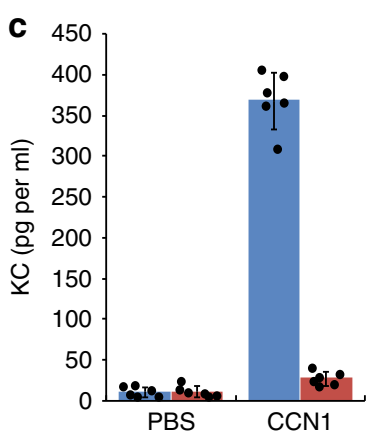
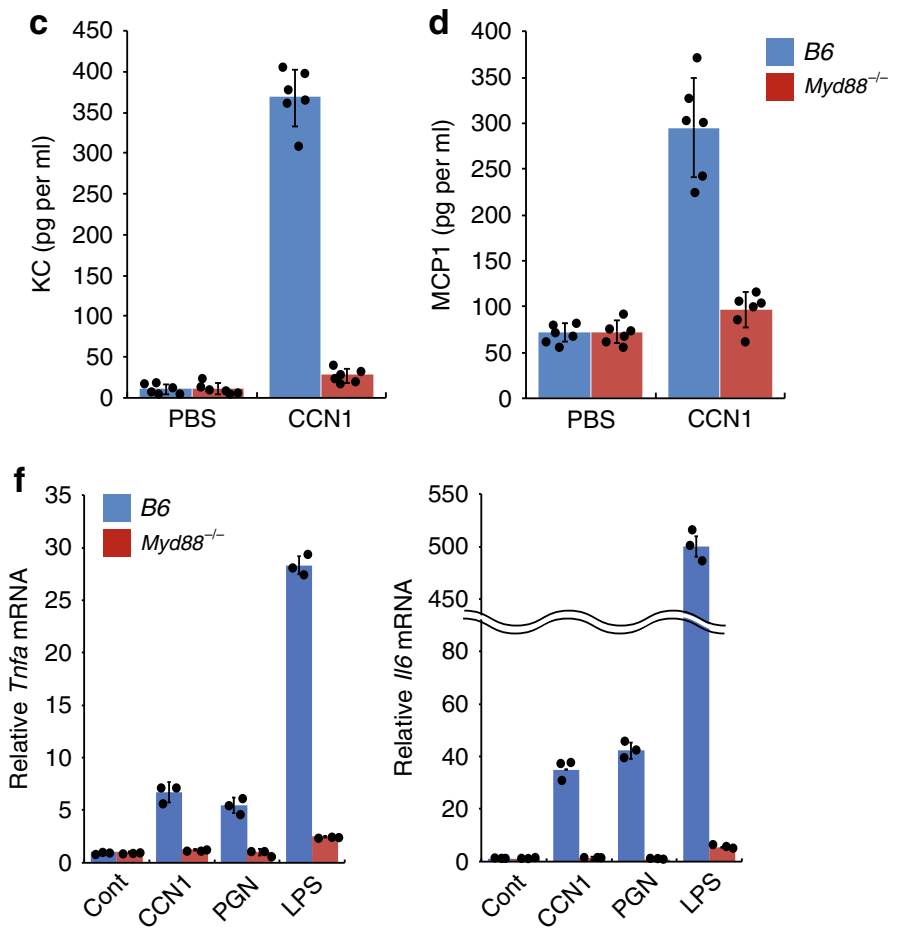

Fig. 7 CCN1 induces Myd88-dependent inflammatory response. a-d C57BL/6J (B6) and Myd88-/- mice $(n=6$ each genotype) were i.p. injected with CCN1 protein ( $5 \mu \mathrm{g}$ in $300 \mu \mathrm{lPBS}$ ), and peritoneal exudates were analyzed for TNF $\alpha$ (30 min) and IL6, KC, and MCP1 (2 h) using ELISA. e Complete blood count (CBC) analysis was performed, and neutrophils and lymphocytes contents are shown. $\mathbf{f}$ Gene expression induced by CCN1. BMDMs from B6 or Myd88-/- mice were treated with CCN1 protein $(2 \mu \mathrm{g}$ per $\mathrm{ml}$ ), LPS (50 $\mathrm{ng}$ per $\mathrm{ml}$ ), or PGN ( $5 \mu \mathrm{g}$ per $\mathrm{ml})$ for $6 \mathrm{~h}$. Tnfa and $116 \mathrm{mRNAs}$ were quantified by qRT-PCR analyses. All data are represented as mean \pm s.d. acquired in triplicate determinations. Statistical evaluation was performed by one-sided, twosample with equal variance $t$-tests. ${ }^{\star \star} p<0.01$, and $n . s .=$ not significant. Source data are provided as a Source Data file.

We have employed two mouse models, Con1 $1^{\Delta M y e l o i d}$ and $C c n 1^{D 125 A / D 125 A}$ mice, to provide genetic evidence for the role of CCN1 in antibacterial defense in vivo (Figs. 4 and 5). First, increased mortality and tissue colonization in $C c n 1^{\Delta M y e l o i d}$ mice upon S. aureus (MRSA USA300) and P. aeruginosa infection clearly demonstrate the importance of $\mathrm{CCN} 1$ expressed in myeloid phagocytes for efficient defense against these pathogens. Second, C $c n 1^{D 125 A / D 125 A}$ knock-in mice exhibited similar defects in bacterial clearance, underscoring the critical role of CCN1 activities mediated through $\alpha_{\mathrm{v}}$ integrins, including phagocytosis and generation of bactericidal ROS (Figs. 2 and 3). Interestingly, some of the distinct phenotypes of these two mouse models also hinted at cell type- and integrin-specific CCN1 functions (Figs. 4d and $5 \mathrm{c}$ ). For example, the formation of pyogenic abscesses was prominent only in $C_{c n} 1^{\Delta \text { Myeloid }}$ mice but not in $C c n 1^{D 125 A / D 125 A}$ mice, suggesting that myeloid cells-derived CCN1 may have negative effects on abscess formation through $\alpha_{\mathrm{v}}$-independent pathways, possibly by regulating bacterial proteins important for abscess formation such as coagulase (Coa) and vWbp ${ }^{66,67}$. By contrast, the $C c n 1^{D 125 A / D 125 A}$ knock-in mice showed shrunken glomeruli and convoluted tubules of the renal cortex area upon $S$. aureus infection (Fig. $5 \mathrm{c}$ ), suggesting that integrin $\alpha_{\mathrm{v}}$-mediated $\mathrm{CCN} 1$ functions in parenchymal tissues may be critical for injury repair ${ }^{68}$. Consistent with a role for $\mathrm{CCN} 1$ in parenchymal repair, CCN1 has been shown to be essential for the regeneration of bile ducts $^{27}$ and the intestinal epithelium ${ }^{28}$ after injuries. In cutaneous wound healing, $\mathrm{CCN} 1$ promotes the removal of apoptotic neutrophils, accelerates wound healing progression ${ }^{25}$, and promotes matrix remodeling ${ }^{26}$. The ability of CCN1 to enhance bacterial clearance may contribute to the healing of wounds at risk of infections. In this regard, $S$. aureus and $P$. aeruginosa are the two most commonly found bacterial pathogens in chronic wounds such as diabetic wounds ${ }^{69,70}$.

To our surprise, we found that $\mathrm{CCN} 1$ can by itself induce inflammatory responses in the absence of bacterial infection through physical interaction with TLR2 and TLR4 to activate MyD88-dependent signaling (Figs. 7 and 8). These findings suggest that CCN1 may act as an alarmin or DAMP to trigger sterile inflammation upon tissue injury to initiate repair. SPR analysis showed that CCN1 binds TLR2 and TLR4 with $K_{\mathrm{D}}$ values of $227 \mathrm{nM}$ and $291 \mathrm{nM}$, respectively. This binding is somewhat stronger than the interaction of HMGB1, a well-characterized DAMP, with the TLR4/MD2 complex $\left(K_{\mathrm{D}}=420 \mathrm{nM}\right)$ or TLR4 alone $\left(K_{\mathrm{D}}=650 \mathrm{nM}\right)^{71}$. Since CCN1 is released from platelet a-granules upon platelet activation ${ }^{72}$, which is triggered by vascular damage, it can be rapidly available upon injury to induce sterile inflammation and tissue repair through direct binding to TLRs. Deregulation of CCN1 may contribute to inflammatory pathologies, as CCN1 has been associated with chronic inflammatory diseases, including rheumatoid arthritis ${ }^{73}$, atherosclerosis ${ }^{74}$, diabetic nephropathy and retinopathy ${ }^{75,76}$, and inflammation-related cancers ${ }^{29}$, and targeting CCN1 with antibodies or siRNAs ameliorates disease symptoms in animal models of rheumatoid arthritis and diabetic retinopathy ${ }^{73,76}$.

As several previous reports on TLR-activating proteins have been confounded by the potential presence of PAMPs in the reagents used ${ }^{51}$, we have reinforced our findings through several lines of evidence. First, our CCN1 proteins were expressed in mycoplasma-free insect cells rather than from bacterial sources. The presence of LPS was not $>0.08 \mathrm{EU}(8 \mathrm{pg})$ per $\mu \mathrm{g}$ CCN1 as judged by the Limulus Amebocyte Lysate (LAL) assay (Supplementary Fig. 14), below the amount necessary to elicit a minimal 

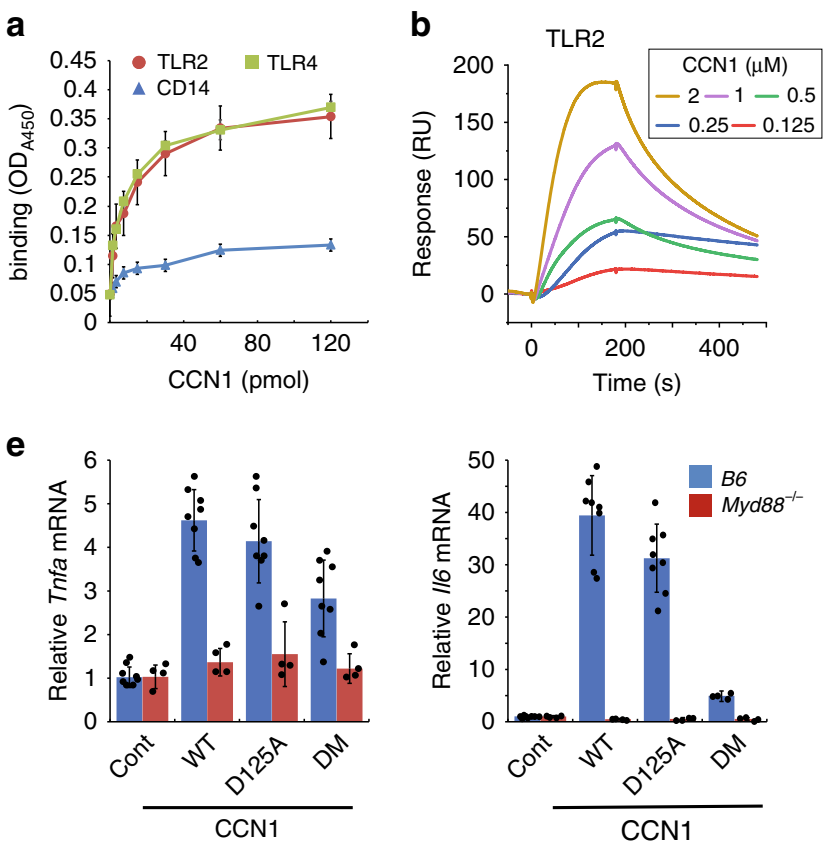

C

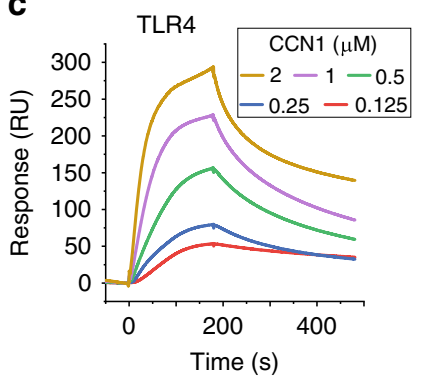

d

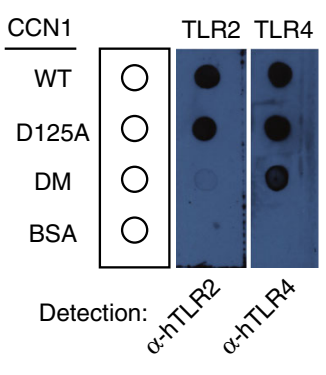

$\mathbf{f}$

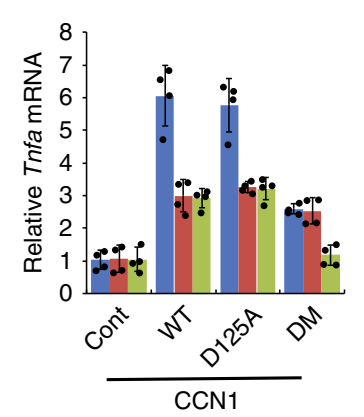

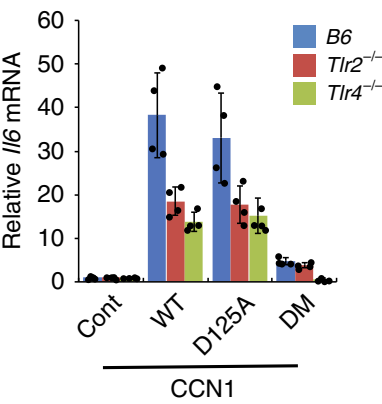

Fig. 8 CCN1 binds and activates TLR2 and TLR4. a Solid-phase-binding assays between CCN1 and TLR2/4. Recombinant TLR2 or TLR4 proteins (200 ng per well) were added to 96-well plates pre-coated with serially diluted CCN1 protein at indicated amounts. Specific interaction was detected and quantified using polyclonal anti-hTLR2 or anti-hTLR4 antibodies. Recombinant CD14 (200 ng per well) was used as a control. b SPR analyses of CCN1 binding to TLR2. TLR2 was immobilized on CM5 chip and various concentrations of CCN1 was injected as analyte. c Sensorgrams of CCN1 binding to TLR4 analyzed by SPR as in $\mathbf{b}$. $\mathbf{d}$ Dot blot analyses of CCN1 and mutant proteins binding to TLR2/4. CCN1-WT, CCN1-D125A, or CCN1-DM proteins (1 $\mu$ g each) were spotted onto nitrocellulose membrane and incubated with TLR2 or TLR4 proteins ( $2 \mu \mathrm{g}$ each in PBS) for $4 \mathrm{~h}$. Binding was detected using polyclonal antihTLR2 or anti-hTLR4 antibodies. A representative image is shown. e Tnfa and 116 mRNAs were quantified in BMDMs from either B6 or MyD88-/- mice treated with CCN1-WT, CCN1-D125A, and CCN1-DM mutant proteins using qRT-PCR analysis. $\mathbf{f}$ Tnfa and $1 / 6$ mRNAs from BMDMs of B6, TIr2-/-, or TIr4 ${ }^{-/-}$mice treated with CCN1 proteins (CCN1-WT, -D125A, -DM, $2 \mu \mathrm{g}$ per ml each) were quantified using qRT-PCR analyses. All data are represented as mean \pm s.d. acquired in triplicate determinations. Statistical evaluation was performed by one-sided, two-sample with equal variance $t$-tests. ${ }^{*} p<0.05$, ${ }^{\star \star} p<0.01$, and $n . s .=$ not significant. Source data are provided as a Source Data file.

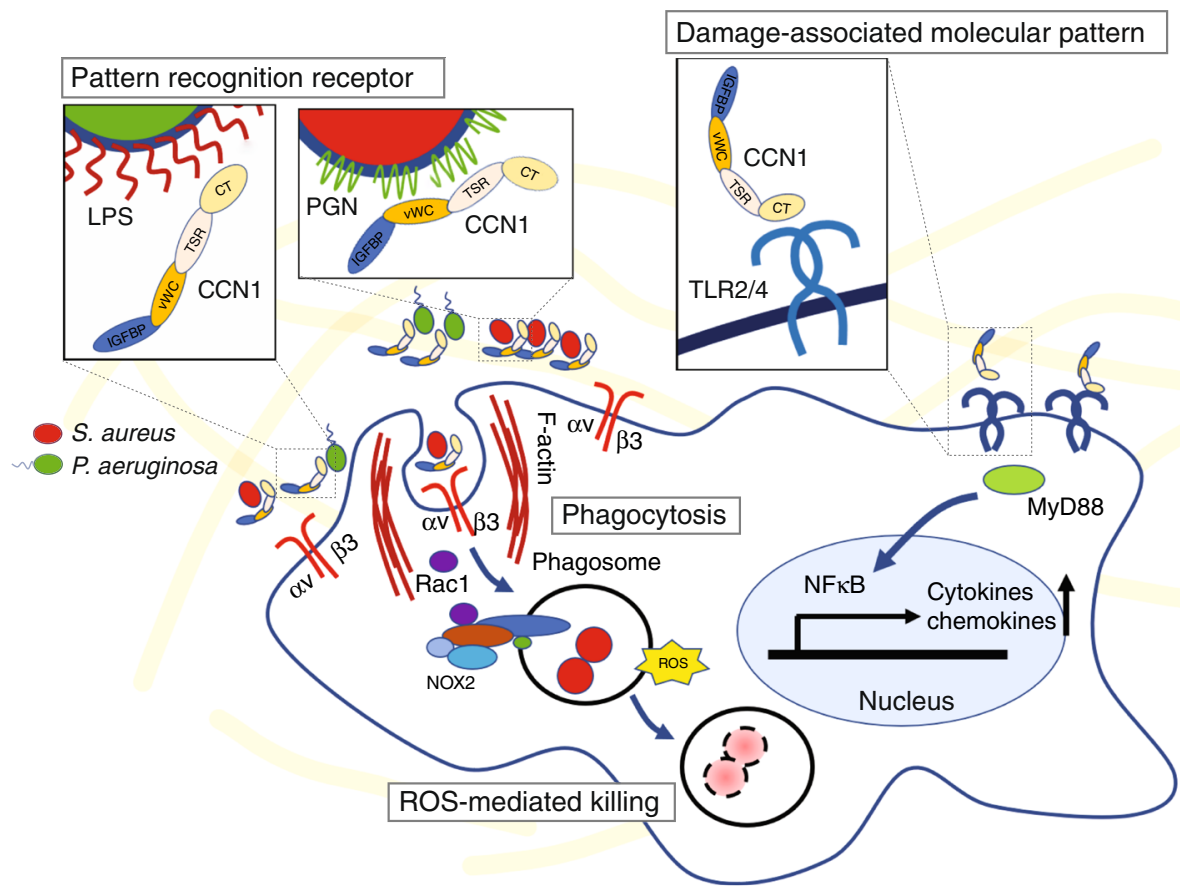

Fig. 9 Schematic of CCN1 functions in bacterial clearance and activation of TLR signaling. CCN1 functions as a PRR and opsonizes Gram-positive and Gram-negative bacteria through binding PGN and LPS, respectively. CCN1 activates phagocytosis by engagement of integrin $\alpha_{v} \beta_{3}$ in phagocytes, thereby promoting the engulfment of bacteria. In macrophages, CCN1 also stimulates ROS production through activation of Rac1 and NOX2, thus enhancing bacterial killing. Independent of the presence of bacteria, CCN1 functions as a DAMP and activates TLR2 and TLR4 by direct binding to these receptors, leading to MyD88-dependent expression of inflammatory cytokines and chemokines. 
discernible induction of cytokine expression in various cell types ${ }^{77}$. Further purification through a polymyxin-B column to remove any residual endotoxin did not change its inflammationinducing activity (Supplementary Fig. 14). Second, the CCN1-DM mutant is unable to bind LPS, yet it can bind TLR4 and induce TLR4 signaling (Figs. $1 \mathrm{~g}$ and $8 \mathrm{f}$ ), indicating CCN1 activation of TLR is independent of LPS binding. Further, CCN1-DM is defective for binding TLR2 and is correspondingly unable to induce TLR2 signaling, indicating that TLR binding and activation require specific sequences in the $\mathrm{CCN} 1$ polypeptide (Fig. 8d, f). Finally, genetic evidence from $\mathrm{Ccn}^{\Delta \text { Myeloid }}$ and $M y d 88^{-/-}$mice showed that $\mathrm{CCN} 1$ contributes to inflammatory responses through MyD88, supporting its functions through TLRs in vivo (Figs. 6 and 7). Altogether, these observations provide compelling evidence that CCN1 acts as a TLR-activating DAMP.

$S$. aureus and $P$. aeruginosa have developed diverse mechanisms of immune evasion by interfering with host opsonins, particularly those that are constitutively expressed ${ }^{78,79}$. For example, mucoid exopolysaccharides from $P$. aeruginosa interferes with complement-dependent phagocytosis ${ }^{80}$, and protein A of $S$. aureus binds to the $\mathrm{Fc}$ region of IgG, thereby blocking FcRdependent phagocytosis ${ }^{81,82}$. However, it appears that neither $S$. aureus nor $P$. aeruginosa has the ability to counteract the opsonin activities of $\mathrm{CCN} 1$, as demonstrated by results in $\mathrm{Ccn} 1$ genetic models and the clear efficacy of exogenous CCN1 in promoting clearance of these bacteria (Figs. 4 and 5, and Supplementary Fig. 10). Furthermore, the activity of CCN1 as an opsonin should be indifferent to the antibiotic resistance status of the bacterial strains. Thus, CCN1 may potentially be useful therapeutically against a broad range of Gram-positive and Gram-negative antibiotics-resistant bacteria. Further studies that define the minimal functional domains of CCN1 for opsonization and phagocytosis may allow the construction of peptides that link these domains for bacterial clearance. Future investigation into the potential efficacy of CCN1 and CCN1-derived peptides may prompt novel therapies for bacterial infections recalcitrant to conventional treatments.

\section{Methods}

CCN1 proteins and reagents. Recombinant CCN1 and mutant proteins (CCN1D125A, CCN1-DM, CCN1- $\Delta$ CT, and IGFBP-vWC; Supplementary Fig. 1) were produced using a baculovirus expression system in $\mathrm{Sf} 9$ insect cells and purified by ion-exchange or immuno-affinity chromatography ${ }^{34,36}$. Sf9 cells were routinely tested for mycoplasma contamination using LookOut ${ }^{\boxplus}$ Mycoplasma PCR detection kit (Sigma, MP0035). CCN1 preparations were tested for the presence of LPS using Limulus Amebocyte Lysate (LAL) Chromogenic Endotoxin Quantification kit (Thermo Scientific, 88282) and found not $>0.08$ EU per $\mu$ g CCN1 (Supplementary Fig. 14A). Further purifications through a polymyxin-B-agarose column (Sigma, P1411; $1 \mathrm{mg}$ per ml; binding capacity of $200-500 \mu \mathrm{g}$ LPS per $1 \mathrm{mg}$ ) to remove any endotoxin did not eliminate CCN1 (Supplementary Fig. 14B). Individual CCN1 domain fragments (IGFBP, vWC, TSR) were produced as GST-fusion proteins and purified using a glutathione-Sepharose column ${ }^{83}$. Additionally, CCN1 proteins were purchased from R\&D biosystems (4055-CR-050) and Novus (NBP2-34944) to test CCN1 activities (Supplementary Fig. 14). Rabbit and goat IgGs were purchased from Fisher Scientific. LPS (L9143) from P. aeruginosa, PGN (77140) and LTA (L2515) from S. aureus, Racl inhibitor (NSC23766; 553502), PI3K inhibitor (LY294002; 19-142), ERK inhibitor (PD98059; 19-143), p38 MAPK inhibitor (SB203580; S8307), cytochalasin D (C2618), and Apocynin (178385) were from Sigma. NOX1 inhibitor (ML-171; 492002) was from EMD Millipore. NOX2 inhibitor (GSK2795039; HY-18950) was from MedChemExpress. Cilengitide (S7707) was from SellecChem.

Bacterial culture. All bacterial stains used were obtained from ATCC. Methicillinresistant S. aureus strain USA300 (ATCC ${ }^{\circledR}-\mathrm{BA}_{1717^{\mathrm{im}}}$ ), P. aeruginosa $\left(\mathrm{ATCC}^{\circledR}{ }_{-}\right.$ $27107^{\mathrm{ms}}$ ), S. pneumoniae (ATCC ${ }^{\circledR}-6303^{\mathrm{ms}}$ ), and S. typhimurium (ATCC ${ }^{\circledR}-14028^{\mathrm{ms}}$ ). S. aureus and $P$. aeruginosa were cultured overnight in tryptic soy broths, diluted at $1: 100$ and grown exponentially. In general, $\mathrm{OD}_{\mathrm{A} 600}=1$ corresponded to $1.5 \times 10^{9}$ $\mathrm{CFU}$ per $\mathrm{ml}$ for $S$. aureus and $7.5 \times 10^{8} \mathrm{CFU}$ per $\mathrm{ml}$ for $P$. aeruginosa. Bacteria were used at their exponential growth phase $\left(\mathrm{OD}_{\mathrm{A} 600}=\sim 0.6\right)$. S. pneumoniae and $S$. typhimurium were grown in Brain-Heart infusion broth (Sigma, 53286).
Animals and bacterial infection models. Animal protocols were approved by the Institutional Animal Care and Use Committee of The University of Illinois at Chicago (ACC\#17-001). Ccn $1^{D 125 A / D 125 A}$ and $C c n 1^{D M / D M}$ knock-in mice ${ }^{25,26}$ were generated in a svJ129-C57BL/6J mixed background and backcrossed to the C57BL/6J strain 6 and 11 times, respectively. Ccn $1^{\Delta M y e l o i d}$ mice were generated by crossing Ccn $1^{\text {flox/flox }}$ with myeloid-specific Cre deleter stain, LysM-Cre (B6.129P2-Lyz2 $\left.2^{\operatorname{tm} 1(\mathrm{cre}) I f o} / \mathrm{J}, 004781\right)$. Tlr2 $2^{-/-}\left(\mathrm{B} 6.129-T l r 2^{\text {tm1Kir }} / \mathrm{J}, 004650\right)$,

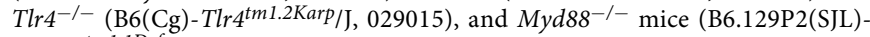
Myd88 $8^{\text {tm1.1Defr } / \mathrm{J}, 009088)}$ were from the Jackson Laboratory. All mice were housed in sterile static microisolator cages on autoclaved corncob bedding with water bottles. Both irradiated food and autoclaved water were provided ad libitum. The standard photoperiod was $14 \mathrm{~h}$ of light and $10 \mathrm{~h}$ of darkness. Mice (both male and female) at 10-12 weeks of age with similar body weight (25-28 g) were used in bacterial infection studies. For bacteremia and tissue colonization studies, mice were anesthetized by intraperitoneal (i.p.) injection of ketamine (100 mg per $\mathrm{kg}$ ) and xylazine (10 $\mathrm{mg}$ per $\mathrm{kg}$ ) and systemically infected with $S$. aureus $\left(7.5 \times 10^{8} \mathrm{CFU}\right.$ per mouse for survival, $2 \times 10^{8} \mathrm{CFU}$ per mouse for tissue colonization) through retro-orbital delivery. Liver (whole-left lateral lobe), kidney (two whole-organs per mouse) and the whole heart were harvested and processed for bacterial colonization and histological analyses. For acute peritonitis model, mice were infected by i.p. injection of $S$. aureus $\left(5 \times 10^{7} \mathrm{CFU}\right.$ per mouse) or $P$. aeruginosa $\left(5 \times 10^{7} \mathrm{CFU}\right.$ per mouse) and peritoneal exudate or whole blood were examined for bacterial blood dissemination and cytokines/ chemokines production. In CCN1 protein injection studies, purified CCN1 (5 $\mu \mathrm{g}$ in PBS) was i.p. injected in animals to analyze inflammatory responses or injected $1 \mathrm{~h}$ after $S$. aureus infection to monitor bacterial clearance. For skin and soft-tissue infection (SSTI), a bolus of $S$. aureus $\left(4 \times 10^{6} \mathrm{CFU}\right.$ per mouse) was subcutaneously injected into mouse flank skin and blood dissemination was monitored.

Complete blood count. Mice with acute peritonitis had total blood drawn via cardiac puncture and complete blood count (CBC) was analyzed using Advia 120 analyzer (Siemens).

Cell culture and isolation. All cell lines were obtained from ATCC. L-929 cells (ATCC ${ }^{\circledR} \mathrm{CCL}-1^{\mathrm{T}}$ ) were grown in Dulbecco's modified Eagle medium (DMEM) Glutamax I media (Invitrogen) supplemented with 10\% (vol per vol) heatinactivated fetal bovine serum (FBS, Hyclone $\left.{ }^{\mathrm{Tw}}\right)$, 1\% HEPES, and $1 \%$ penicillinstreptomycin (Invitrogen) in a humidified incubator with $5 \% \mathrm{CO}_{2}$ at $37^{\circ} \mathrm{C}$. For preparation of conditioned medium, L-929 cells were plated at density of $4.7 \times 10^{5}$ cells in a $75-\mathrm{cm}^{2}$ flask containing $55 \mathrm{ml}$ culture medium and grown for 7 days. Collected supernatant was filtered through a $0.45 \mu \mathrm{m}$ filter and stored at $-30^{\circ} \mathrm{C}$. THP.1 cells (ATCC ${ }^{\circledR}$ TIB-202 $2^{\text {rx }}$ ) were grown in suspension in RPMI Glutamax media (Invitrogen) supplemented with $10 \%$ FBS and $0.05 \mathrm{mM} \beta$-mercaptoethanol. For differentiation, THP.1 cells at low passage $(<15)$ were plated in 4 -well chamber slide in the presence of phorbol-12-myristate-13-acetate (PMA, $100 \mathrm{nM}$; Sigma) for 3 days. Peritoneal macrophages were isolated from peritoneal exudates of mice elicited with thioglycolate ( $3 \%$ vol per weight) for 3 days $^{84}$. Bone marrow-derived neutrophils (PMNs) were isolated by differential centrifugation ${ }^{25}$. The purity of the neutrophil fraction was assessed by Giemsa staining (Sigma); over 99\% purity was typically obtained. For BMDMs, the total bone-marrow cells were re-suspended in macrophage complete media (DMEM/F12 with 10\% FBS and 20\% L-929 cells conditioned media), and $4 \times 10^{5}$ cells were plated in sterile plastic petri dish (100 $\mathrm{mm}$ ) and incubated in $5 \% \mathrm{CO}_{2}$ at $37^{\circ} \mathrm{C}$ for 7 days with medium being refreshed every 3 days for differentiation into macrophages. Macrophage differentiation was assessed by F4/80 immunostaining; typically, over $90 \%$ are F4/80 positive. For splenic B or T cells isolation, total spleen was excised and homogenized between frosted ends of microscope slides in Hank's Balanced Salt Solution. Subsequently, B or T cells were isolated using Nylon Wool Fiber Columns (Polysciences) according to manufacturer's instruction.

Bacterial phagocytosis and killing. For S. aureus phagocytosis, BMDMs were labeled with CellTracker ${ }^{2 \pi}$ Green-CMFDA (5-chloromethylfluorescein diacetate) fluorescent dye $(5 \mu \mathrm{M}$, Invitrogen) for $30 \mathrm{~min}$. Cells were either untreated or pretreated with CCN1 proteins (CCN1-WT, -D125A, and -DM; $2 \mu \mathrm{g}$ per ml each) for $1 \mathrm{~h}$, followed by incubation with $S$. aureus bioparticle (pHrodo ${ }^{\circledR}$ Red $S$. aureus BioParticles $^{\text {tx }}$ conjugates; Invitrogen, $5 \mu \mathrm{g}$ per $\mathrm{ml}$ ) for an additional $45 \mathrm{~min}$. Cells were washed with ice-cold PBS five times and fixed with paraformaldehyde ( $4 \% \mathrm{vol}$ per vol in PBS). Images were taken using fluorescence microscopy (Leica DM4000B). Phagocytosis was quantified by counting macrophages containing $>2 S$. aureus particles in 12 randomly selected high-powered fields and expressed as a percentage of positive macrophages over total cells counted ( 300 cells). For all inhibitor experiments, cells were pretreated with chemical inhibitors for $30 \mathrm{~min}$ prior to CCN1 treatment. To monitor bacterial killing after phagocytosis, BMDMs were allowed to phagocytose S. aureus (MOI of 10) for $90 \mathrm{~min}$, followed by CCN1 treatment with or without chemical inhibitors. To remove unphagocytosed $S$. aureus, lysostaphin (10 $\mu$ g per $\mathrm{ml}$; Sigma) was added for $15 \mathrm{~min}$. Cells were lysed in Triton X-100 ( $0.04 \%$ vol per vol) and plated with serial dilution on tryptic soy agar plates with $5 \%$ sheep blood for bacterial enumeration. 
To monitor phagocytosis of $P$. aeruginosa, BMDMs were pretreated with CCN1 proteins, followed by incubation with $P$. aeruginosa (MOI of 10) for $45 \mathrm{~min}$. Cells were treated with gentamycin ( $200 \mu \mathrm{g}$ per $\mathrm{ml}$; Gibco) for $15 \mathrm{~min}$ to eliminate extracellular or membrane-bound bacteria, lysed in Triton X-100 $(0.04 \%$ vol per $\mathrm{vol}$ ), and plated with serial dilution on tryptic soy agar with $5 \%$ sheep blood for bacterial enumeration.

ROS measurement. For measurement of superoxide radicals $\left(\mathrm{O}_{2}{ }^{-}\right)$, BMDMs were grown in 4-well chamber slides and pre-loaded with dihydroethidium (DHE, $5 \mu \mathrm{M}$; Invitrogen) in serum-free media for $1 \mathrm{~h}$. Cells were then treated with CCN1 proteins in full growth media for an additional $45 \mathrm{~min}$ and washed with ice-cold PBS three times. High-resolution images were taken from randomly selected fields using fluorescence microscopy (Leica DM4000B) and fluorescence intensity of individual cells ( $>50$ cells) was analyzed using Image J (NIH). Chemical inhibitors were treated $30 \mathrm{~min}$ prior to $\mathrm{CCN} 1$ proteins. Cells were kept in darkness during the entire procedure.

Solid-phase-binding assay and dot blot analysis. The physical interaction of CCN1 with bacteria (S. aureus or P. aeruginosa) or TLRs was analyzed in solidphase-binding assays. Ninety-six-well plates were coated with serially diluted CCN1 or other ECM proteins in bicarbonate/carbonate coating buffer $(100 \mathrm{mM}$, $\mathrm{pH}$ 9.6) overnight at $4^{\circ} \mathrm{C}$. After washing three times with PBS-Tween20 (PBST), plates were then blocked with poly-vinyl alcohol (PVA, $2 \%$ vol per weight) for $1 \mathrm{~h}$. For bacterial binding, S. aureus or $P$. aeruginosa $\left(8 \times 10^{3} \mathrm{CFU}\right.$ per well in $100 \mu \mathrm{l}$ PBS) was added to each well and incubated for $1 \mathrm{~h}$. After washing with PBST three times, bound bacteria were detected using polyclonal anti-S. aureus (abcam, ab20920; 1:2000 dilution) or anti-P. aeruginosa antibodies (abcam, ab69232; 1:500 dilution), visualized with horseradish peroxidase (HRP)-conjugated secondary antibodies with $3,3^{\prime}, 5,5^{\prime}$ - Tetramethylbenzidine (TMB) as a substrate, and quantified in a microplate reader (Labsystems Multiskan MS) at A450 nm. Absorbance at A570 $\mathrm{nm}$ was used to correct for minor optical imperfections of plates. All assays were done in triplicates and in three independent experiments. For TLRs interaction, hTLR2, hTLR4, or hCD14 (0.2 $\mu \mathrm{g}$ per well, R\&D systems) were incubated with coated CCN1 proteins and detected using polyclonal anti-hTLR2 (AF2616), anti-hTLR4 (AF1478), or monoclonal anti-hCD14 antibodies (MAB3832, R\&D systems; 1:100 dilution each,) as described above. In some cases, interactions were assayed in dot blot analyses. Briefly, bacterial pattern molecules (PGN, LTA, or LPS; $1 \mu \mathrm{g}$ each) were spotted on nitrocellulose membranes and air-dried for $30 \mathrm{~min}$. Each membrane was incubated with CCN1 proteins (CCN1-WT, -D125A, or -DM proteins; $5 \mu \mathrm{g}$ in $5 \mathrm{ml} \mathrm{PBS}$ each) and bound $\mathrm{CCN} 1$ was detected with polyclonal anti-CCN1 antibodies (1:2000 dilution) using chemiluminescence. For TLRs binding, CCN1 proteins (CCN1-WT, -D125A, and -DM; $1 \mu \mathrm{g}$ each) were spotted, followed by incubation with hTLR2 or hTLR4 (each $5 \mu \mathrm{g}$ in $5 \mathrm{ml}$ PBS). Bound TLRs were detected with polyclonal anti-hTLR2 or anti-hTLR4 antibodies (1:1000 dilution each)

Flow cytometry. S. aureus collected in the logarithmic phase were heat-killed in $80^{\circ} \mathrm{C}$ for $30 \mathrm{~min}$ and re-suspended in PBS buffer containing $2 \mathrm{mM}$ EDTA and $0.5 \%$ BSA. S. aureus $\left(10^{8} \mathrm{CFU}\right.$ per $\left.\mathrm{ml}\right)$ were then incubated with increasing concentrations of either CCN1 or recombinant human C3b complement proteins (Sigma, 204860) for $1 \mathrm{~h}$ at room temperature. After washing once with buffer, rabbit polyclonal anti-CCN1 antibody (1:100 dilution) or mouse monoclonal antiiC3b antibody (EMD Millipore, MABF972; 1:200 dilution) were added for $1 \mathrm{~h}$, followed by allophycocyanin (APC)-conjugated goat anti-rabbit IgGs (Life Technologies Co.; A10931, 1:250 dilution;) or APC-conjugated rat anti-mouse IgGs (Life Technologies Co.; 17-4015-82, 1:500 dilution), respectively. S. aureus was then analyzed using CytoFLEX S flow cytometer (APC channel, Beckman Coulter) and histograms were generated using CytoExpert software. The gating strategy is shown in Supplementary Fig. 2.

SPR analysis. SPR studies were performed using a Biacore T-200 (Biacore Inc., GE Healthcare) biosensor system according to the manufacturer's instructions. TLR2, TLR4 and integrin $\alpha_{v} \beta_{3}$ proteins were directly immobilized on a CM5 sensor chip using the standard amine-coupling method. The carboxymethylated dextran surface was activated by 1-ethyl-3-(3-dimethylaminoprophyl) carbodiimide hydrochloride (EDC)/N-hydroxy succinimide (NHS) mixture. TLR2 (2616-TR-050, R\&D systems), TLR4 (1478-TR-050) and integrin $\alpha_{\mathrm{v}} \beta_{3}$ proteins (3050-AV-050) were diluted with $10 \mathrm{mM}$ sodium acetate buffers ( $\mathrm{pH} 4.0$ ) and immobilized on respective flow channels, followed by ethanolamine blocking of the unoccupied surface area. As an analyte, various concentrations of CCN1 were applied at $25 \mu \mathrm{l}$ per min flow rate at $25^{\circ} \mathrm{C}$ in phosphate buffer containing $350 \mathrm{mM}$ sodium chloride, $0.5 \mathrm{mM}$ calcium chloride and $0.5 \mathrm{mM}$ magnesium chloride and $10 \mu \mathrm{g}$ per $\mathrm{ml}$ BSA. LPS was immobilized on a hydrophobic HPA sensor chip and CCN1 protein was used as analyte. For immobilization, the HPA surface was washed with a 5-min injection of $40 \mathrm{mM}$ octyl glucoside in water, followed by LPS injection at a low flow rate $(5 \mu \mathrm{l}$ per $\mathrm{min})$. Loosely bound LPS was then removed by washing the surface with a short injection ( $1 \mathrm{~min}$ ) of $100 \mathrm{mM}$ sodium hydroxide. The instrument was kept completely detergent-free and buffers were thoroughly degassed for experiment with HPA chip as recommended. Data (response unit, RU) were double subtracted by blank reference channel and zero concentration analyte signal. Sensorgrams were analyzed using the Biacore T-200 evaluation software V.3.0 and kinetic rate constants $\left(k_{a}\right.$ and $k_{d}$ ) were determined by fitting globally to the 1:1 Langmuir (one-to-one binding) model embedded within the software. The equilibrium dissociation constant $\left(K_{\mathrm{D}}\right)$ was calculated as the ratio of these two constants $\left(k_{d} / k_{a}\right)$.

Tissue histology. Liver and kidney tissues from mice at 5 day post infection were snap-frozen in optimum cutting temperature (OCT) compound (Tissue-Tek) and sectioned serially $(7 \mu \mathrm{m})$ using a Leica CM1950 UV cryostat. Sections fixed with cold acetone were stained with Hematoxylin/Eosin (H\&E) or probed with polyclonal anti-S. aureus antibodies (abcam; ab20920, 1:100 dilution) in immunofluorescence staining using Alexafluor488-conjugated anti-rabbit IgG (Invitrogen, 1:500 dilution). DAPI was used as the counterstain ( $1 \mathrm{mg}$ per ml, Sigma). Fluorescence images were acquired using a Leica DM4000B microscope and processed with Photoshop CC 2019 (Adobe).

Knockdown of integrin subunit in BMDMs. Predesigned Dicer-Substrate Short Interfering RNAs (DsiRNAs, $2 \mathrm{nM}$; Integrated DNA Technologies) against specific integrin subunits were transfected into BMDMs using SuperFect Transfection reagent (Qiagen) according to manufacturer's manuals. Knockdown efficiencies $(>90 \%)$ were confirmed using quantitative reverse transcription PCR (qRT-PCR) analyses after $24 \mathrm{~h}$. DsiRNA sequences used for knockdown are shown in Supplementary Table 1.

Quantification of cytokines and chemokines. Mice were challenged with acute peritonitis induced by either S. aureus infection or CCN1 injection. Peritoneal exudates were harvested with $4 \mathrm{ml}$ ice-cold PBS using 18-gauge needles; cytokines and chemokines were quantified using ELISA kits: mTNFa (88-7324-22, eBioscience), mIL6 (88-7064-22, eBioscience), KC (EMCXCL1, Invitrogen), and mMCP-1 (88-7391-22, Fisher Scientific).

RNA isolation and qRT-PCR. Cultured BMDMs were homogenized using TRIzol reagent (Invitrogen) and total RNAs were purified using RNeasy ${ }^{\oplus}$ Mini Kit (Qiagen). Total RNAs $(2 \mu \mathrm{g})$ were reverse transcribed to complementary DNA using MMLV Reverse Transcriptase (Promega), and qRT-PCR was performed with the iCycler Thermal Cycler (Bio-Rad) using iQ SYBR Green Supermix (Bio-Rad). The specificity of qRT-PCR was confirmed by agarose gel electrophoresis and melting curve analysis. A housekeeping gene (Cyclophilin E) was used as an internal control. The primers used are following: Tnfa, forward 5'-CATCTTCTCAAAATTCGAGTGACAA-3', reverse 5'-TGGGAGTAGACAAGGTACAACCC-3'; Il6, forward 5-GAGGATACC ACTCCCAACGAGCC-3' , reverse 5'-AAGTGCATCATCGTTGTTCATACA-3'; Cyclophilin E (CypE), forward 5'-TTCACAAACCACAATGGCACAGGG-3', reverse 5'-TGCCGTCCAGCCAATCTGTCTTAT- 3 '.

Statistics. All experimental results are expressed either as mean \pm standard deviation (s.d.) or mean with individual quantitative values in dot plots. Wherever necessary, statistical evaluation was performed by one-sided, two-sample with equal variance $t$-tests. A $p<0.05$ value was considered significant. All quantitative experiments were performed in triplicates unless otherwise indicated.

Reporting summary. Further information on research design is available in the Nature Research Reporting Summary linked to this article.

\section{Data availability}

Data supporting the findings of this work are available within the paper and the Supplementary Information files. The raw data are provided in Source Data file or from the corresponding author upon request.

Received: 23 May 2019; Accepted: 17 February 2020; Published online: 06 March 2020

\section{References}

1. Naylor, N. R. et al. Estimating the burden of antimicrobial resistance: a systematic literature review. Antimicrob. Resist. Infect. Control 7, 58 (2018).

2. Centers for Disease Control and Prevention. Antibiotic resistance threats in the United States 2019. Available at https://www.cdc.gov/drugresistance/pdf/ threats-report/2019-ar-threats-report-508.pdf (accessed: 9th Jan 2020) (2019)

3. Interagency Coordination Group on Antimicrobial Resistance. No time to wait: Securing the future from drug-resistant infections. Report to the Secretary-General of the United Nations. Available at https://www.who.int/ antimicrobial-resistance/interagency-coordination-group/ IACG_final_report_EN.pdf?ua=1 (accessed: 2 Nov 2019) (2019). 
4. Partridge, S. R., Kwong, S. M., Firth, N. \& Jensen, S. O. Mobile genetic elements associated with antimicrobial resistance. Clin. Microbiol. Rev. 31, e00088-00017 (2018).

5. Kallen, A. J. et al. Health care-associated invasive MRSA infections, 2005-2008. JAMA 304, 641-648 (2010).

6. David, M. Z. \& Daum, R. S. Community-associated methicillin-resistant Staphylococcus aureus: epidemiology and clinical consequences of an emerging epidemic. Clin. Microbiol. Rev. 23, 616-687 (2010).

7. Lee, A. S. et al. Methicillin-resistant Staphylococcus aureus. Nat. Rev. Dis. Prim. 4, 18033 (2018).

8. Turner, N. A. et al. Methicillin-resistant Staphylococcus aureus: an overview of basic and clinical research. Nat. Rev. Microbiol. 17, 203-218 (2019).

9. Flamm, R. K. et al. Factors associated with relative rates of antibiotic resistance in Pseudomonas aeruginosa isolates tested in clinical laboratories in the United States from 1999 to 2002. Antimicrob. Agents Chemother. 48, 2431-2436 (2004).

10. Holtfreter, S. et al. Antibody responses in furunculosis patients vaccinated with autologous formalin-killed Staphylococcus aureus. Eur. J. Clin. Microbiol. Infect. Dis. 30, 707-717 (2011).

11. DiGiandomenico, A. et al. Intranasal immunization with heterologously expressed polysaccharide protects against multiple Pseudomonas aeruginosa infections. Proc. Natl Acad. Sci. USA 104, 4624-4629 (2007).

12. Epelman, S., Lavine, K. J. \& Randolph, G. J. Origin and functions of tissue macrophages. Immunity 41, 21-35 (2014).

13. Andrews, T. \& Sullivan, K. E. Infections in patients with inherited defects in phagocytic function. Clin. Microbiol. Rev. 16, 597-621 (2003)

14. Akira, S., Uematsu, S. \& Takeuchi, O. Pathogen recognition and innate immunity. Cell 124, 783-801 (2006).

15. Nguyen, M. T., Peisl, L., Barletta, F., Luqman, A. \& Gotz, F. Toll-like receptor 2 and lipoprotein-like lipoproteins enhance Staphylococcus aureus invasion in epithelial cells. Infect. Immun. 86, e00343-00318 (2018).

16. Tricker, E. \& Cheng, G. With a little help from my friends: modulation of phagocytosis through TLR activation. Cell Res. 18, 711-712 (2008).

17. Frevert, C. W., Felgenhauer, J., Wygrecka, M., Nastase, M. V. \& Schaefer, L. Danger-associated molecular patterns derived from the extracellular matrix provide temporal control of innate immunity. J. Histochem. Cytochem. 66, 213-227 (2018).

18. Gong, T., Liu, L., Jiang, W. \& Zhou, R. DAMP-sensing receptors in sterile inflammation and inflammatory diseases. Nat. Rev. Immunol. 20, 95-112 (2020).

19. Geijtenbeek, T. B. \& Gringhuis, S. I. Signalling through C-type lectin receptors: shaping immune responses. Nat. Rev. Immunol. 9, 465-479 (2009).

20. Zani, I. A. et al. Scavenger receptor structure and function in health and disease. Cells 4, 178-201 (2015).

21. Wieland, A. \& Ahmed, R. Fc receptors in antimicrobial protection. Curr. Top. Microbiol. Immunol. 423, 119-150 (2019).

22. van Lookeren Campagne, M., Wiesmann, C. \& Brown, E. J. Macrophage complement receptors and pathogen clearance. Cell. Microbiol. 9, 2095-2102 (2007).

23. Mo, F. E. et al. CYR61 (CCN1) is essential for placental development and vascular integrity. Mol. Cell. Biol. 22, 8709-8720 (2002).

24. Mo, F. E. \& Lau, L. F. The matricellular protein CCN1 is essential for cardiac development. Circ. Res. 99, 961-969 (2006)

25. Jun, J. -I., Kim, K. -H. \& Lau, L. F. The matricellular protein CCN1 mediates neutrophil efferocytosis in cutaneous wound healing. Nat. Commun. 6, 7386 (2015).

26. Jun, J. -I. \& Lau, L. F. The matricellular protein CCN1 induces fibroblast senescence and restricts fibrosis in cutaneous wound healing. Nat. Cell. Biol. 12, 676-685 (2010).

27. Kim, K. -H., Chen, C. -C., Alpini, G. \& Lau, L. F. CCN1 induces hepatic ductular reaction through integrin $\alpha v \beta 5$-mediated activation of NF- $\mathrm{kB} . J$. Clin. Invest. 125, 1886-1900 (2015).

28. Choi, J. S., Kim, K. H. \& Lau, L. F. The matricellular protein CCN1 promotes mucosal healing in murine colitis through IL-6. Mucosal Immunol. 8 1285-1296 (2015)

29. Jun, J. -I. \& Lau, L. F. Taking aim at the extracellular matrix: CCN proteins as emerging therapeutic targets. Nat. Rev. Drug Discov. 10, 945-963 (2011).

30. Lau, L. F. CCN1/CYR61: the very model of a modern matricellular protein. Cell. Mol. Life Sci. 68, 3149-3163 (2011).

31. Lau, L. F. Cell surface receptors for CCN proteins. J. Cell Commun. Signal. 10, 121-127 (2016).

32. Geraci, J. et al. The Staphylococcus aureus extracellular matrix protein (Emp) has a fibrous structure and binds to different extracellular matrices. Sci. Rep. 7, 13665 (2017)

33. Montgomery, C. P. et al. Comparison of virulence in community-associated methicillin-resistant Staphylococcus aureus pulsotypes USA300 and USA400 in a rat model of pneumonia. J. Infect. Dis. 198, 561-570 (2008).
34. Chen, N., Leu, S. J., Todorovic, V., Lam, S. C. \& Lau, L. F. Identification of a novel integrin alphavbeta3 binding site in CCN1 (CYR61) critical for proangiogenic activities in vascular endothelial cells. J. Biol. Chem. 279, 44166-44176 (2004).

35. Chen, N., Chen, C. C. \& Lau, L. F. Adhesion of human skin fibroblasts to Cyr61 is mediated through integrin alpha 6beta 1 and cell surface heparan sulfate proteoglycans. J. Biol. Chem. 275, 24953-24961 (2000).

36. Leu, S. J. et al. Targeted mutagenesis of the angiogenic protein $\mathrm{CCN1}$ (CYR61). Selective inactivation of integrin alpha6beta1-heparan sulfate proteoglycan coreceptor-mediated cellular functions. J. Biol. Chem. 279, 44177-44187 (2004)

37. Dustin, M. L. Complement receptors in myeloid cell adhesion and phagocytosis. Microbiol. Spectr. 4, https://doi.org/10.1128/microbiolspec. MCHD-0034-2016 (2016).

38. Hochreiter-Hufford, A. \& Ravichandran, K. S. Clearing the dead: apoptotic cell sensing, recognition, engulfment, and digestion. Cold Spring Harb. Perspect. Biol. 5, a008748 (2013).

39. Schlam, D. et al. Phosphoinositide 3-kinase enables phagocytosis of large particles by terminating actin assembly through Rac/Cdc42 GTPase-activating proteins. Nat. Commun. 6, 8623 (2015).

40. Pauwels, A. M., Trost, M., Beyaert, R. \& Hoffmann, E. Patterns, receptors, and signals: regulation of phagosome maturation. Trends Immunol. 38, 407-422 (2017).

41. Chen, C. -C. et al. Cytotoxicity of TNFalpha is regulated by integrin-mediated matrix signaling. EMBO J. 26, 1257-1267 (2007).

42. Bastos, M. D., Coutinho, B. G. \& Coelho, M. L. Lysostaphin: a staphylococcal bacteriolysin with potential clinical applications. Pharmaceuticals (Basel) 3 , 1139-1161 (2010)

43. Brune, B. et al. Redox control of inflammation in macrophages. Antioxid. Redox Signal. 19, 595-637 (2013).

44. Zhao, X., Carnevale, K. A. \& Cathcart, M. K. Human monocytes use Rac1, not Rac2, in the NADPH oxidase complex. J. Biol. Chem. 278, 40788-40792 (2003)

45. Kim, C. \& Dinauer, M. C. Rac2 is an essential regulator of neutrophil nicotinamide adenine dinucleotide phosphate oxidase activation in response to specific signaling pathways. J. Immunol. 166, 1223-1232 (2001).

46. Holland, T. L., Arnold, C. \& Fowler, V. G. Jr. Clinical management of Staphylococcus aureus bacteremia: a review. JAMA 312, 1330-1341 (2014).

47. van Hal, S. J. et al. Predictors of mortality in Staphylococcus aureus Bacteremia. Clin. Microbiol. Rev. 25, 362-386 (2012).

48. Thomer, L., Schneewind, O. \& Missiakas, D. Pathogenesis of Staphylococcus aureus bloodstream infections. Annu. Rev. Pathol. 11, 343-364 (2016).

49. Ray, G. T., Suaya, J. A. \& Baxter, R. Microbiology of skin and soft tissue infections in the age of community-acquired methicillin-resistant Staphylococcus aureus. Diagn. Microbiol. Infect. Dis. 76, 24-30 (2013).

50. Deguine, J. \& Barton, G. M. MyD88: a central player in innate immune signaling. F1000Prime Rep. 6, 97 (2014).

51. Erridge, C. Endogenous ligands of TLR2 and TLR4: agonists or assistants? J. Leukoc. Biol. 87, 989-999 (2010).

52. Flannagan, R. S., Jaumouille, V. \& Grinstein, S. The cell biology of phagocytosis. Annu. Rev. Pathol. 7, 61-98 (2012).

53. An, J. H. et al. Human SAP is a novel peptidoglycan recognition protein that induces complement-independent phagocytosis of Staphylococcus aureus. J. Immunol. 191, 3319-3327 (2013).

54. Lu, J., Mold, C., Du Clos, T. W. \& Sun, P. D. Pentraxins and Fc receptormediated immune responses. Front. Immunol. 9, 2607 (2018).

55. Neth, O. et al. Mannose-binding lectin binds to a range of clinically relevant microorganisms and promotes complement deposition. Infect. Immun. 68, 688-693 (2000)

56. Matsushita, M. Ficolins in complement activation. Mol. Immunol. 55, 22-26 (2013).

57. Penberthy, K. K. \& Ravichandran, K. S. Apoptotic cell recognition receptors and scavenger receptors. Immunol. Rev. 269, 44-59 (2016).

58. Rennemeier, C. et al. Thrombospondin-1 promotes cellular adherence of gram-positive pathogens via recognition of peptidoglycan. FASEB J. 21, 3118-3132 (2007)

59. He, Y. W. et al. The extracellular matrix protein mindin is a patternrecognition molecule for microbial pathogens. Nat. Immunol. 5, 88-97 (2004)

60. Das, S. et al. Brain angiogenesis inhibitor 1 (BAI1) is a pattern recognition receptor that mediates macrophage binding and engulfment of Gram-negative bacteria. Proc. Natl Acad. Sci. USA 108, 2136-2141 (2011).

61. Gordon, S. Phagocytosis: an immunobiologic process. Immunity 44, 463-475 (2016).

62. Mao, Y. \& Finnemann, S. C. Regulation of phagocytosis by Rho GTPases. Small GTPases 6, 89-99 (2015).

63. Lawson, C. D. \& Burridge, K. The on-off relationship of Rho and Rac during integrin-mediated adhesion and cell migration. Small GTPases 5, e27958 (2014).

64. Park, D. et al. BAIl is an engulfment receptor for apoptotic cells upstream of the ELMO/Dock180/Rac module. Nature 450, 430-434 (2007). 
65. Smith, H. W., Marra, P. \& Marshall, C. J. uPAR promotes formation of the p130Cas-Crk complex to activate Rac through DOCK180. J. Cell Biol. 182, 777-790 (2008).

66. Friedrich, R. et al. Staphylocoagulase is a prototype for the mechanism of cofactor-induced zymogen activation. Nature 425, 535-539 (2003).

67. Cheng, A. G. et al. Contribution of coagulases towards Staphylococcus aureus disease and protective immunity. PLoS Pathog. 6, e1001036 (2010).

68. Sawai, K. et al. Angiogenic protein Cyr61 is expressed by podocytes in antiThy-1 glomerulonephritis. J. Am. Soc. Nephrol. 14, 1154-1163 (2003)

69. Trivedi, U. et al. Prevalence of multiple antibiotic resistant infections in diabetic versus nondiabetic wounds. J. Pathog. 2014, 173053 (2014).

70. Fazli, M. et al. Nonrandom distribution of Pseudomonas aeruginosa and Staphylococcus aureus in chronic wounds. J. Clin. Microbiol. 47, 4084-4089 (2009).

71. He, M., Bianchi, M. E., Coleman, T. R., Tracey, K. J. \& Al-Abed, Y. Exploring the biological functional mechanism of the HMGB1/TLR4/MD-2 complex by surface plasmon resonance. Mol. Med. 24, 21 (2018).

72. Hviid, C. V. et al. The matricellular "cysteine-rich protein 61 " is released from activated platelets and increased in the circulation during experimentally induced sepsis. Shock 41, 233-240 (2014).

73. Chen, C. Y. et al. Enhancement of CCL2 expression and monocyte migration by CCN1 in osteoblasts through inhibiting miR-518a-5p: implication of rheumatoid arthritis therapy. Sci. Rep. 7, 421 (2017).

74. Schober, J. M. et al. Identification of integrin alpha(M)beta(2) as an adhesion receptor on peripheral blood monocytes for Cyr61 (CCN1) and connective tissue growth factor (CCN2): immediate-early gene products expressed in atherosclerotic lesions. Blood 99, 4457-4465 (2002).

75. Hughes, J. M. et al. Advanced glycation end products cause increased CCN family and extracellular matrix gene expression in the diabetic rodent retina. Diabetologia 50, 1089-1098 (2007).

76. You, J. J., Yang, C. H., Chen, M. S. \& Yang, C. M. Cysteine-rich 61, a member of the CCN family, as a factor involved in the pathogenesis of proliferative diabetic retinopathy. Invest. Ophthalmol. Vis. Sci. 50, 3447-3455 (2009).

77. Schwarz, H., Schmittner, M., Duschl, A. \& Horejs-Hoeck, J. Residual endotoxin contaminations in recombinant proteins are sufficient to activate human CD1c+ dendritic cells. PLoS ONE 9, e113840 (2014).

78. Finlay, B. B. \& McFadden, G. Anti-immunology: evasion of the host immune system by bacterial and viral pathogens. Cell 124, 767-782 (2006).

79. Reddick, L. E. \& Alto, N. M. Bacteria fighting back: how pathogens target and subvert the host innate immune system. Mol. Cell 54, 321-328 (2014).

80. Leid, J. G. et al. The exopolysaccharide alginate protects Pseudomonas aeruginosa biofilm bacteria from IFN-gamma-mediated macrophage killing. J. Immunol. 175, 7512-7518 (2005).

81. Kim, H. K. et al. Protein A-specific monoclonal antibodies and prevention of Staphylococcus aureus disease in mice. Infect. Immun. 80, 3460-3470 (2012).

82. Kobayashi, S. D. \& DeLeo, F. R. Staphylococcus aureus protein A promotes immune suppression. mBio 4, e00764-00713 (2013).

83. Leu, S. J. et al. Identification of a novel integrin alpha 6 beta 1 binding site in the angiogenic inducer CCN1 (CYR61). J. Biol. Chem. 278, 33801-33808 (2003).
84. Bai, T., Chen, C. C. \& Lau, L. F. Matricellular protein CCN1 activates a proinflammatory genetic program in murine macrophages. J. Immunol. 184, 3223-3232 (2010)

\section{Acknowledgements}

We thank Dr. Hyun Lee of the UIC Biophysics Core for help with SPR analysis and Seung Won Shin for excellent assistance. This work was supported by grants from the National Institutes of Health (AR061791, GM078492, and DK108994) to L.F.L.

\section{Author contributions}

J.-I.J. conducted the experiments; J.-I.J. and L.F.L. designed the experimental plan, analyzed the data, and wrote the paper.

\section{Competing interests}

The authors declare no competing interests.

\section{Additional information}

Supplementary information is available for this paper at https://doi.org/10.1038/s41467020-15075-5.

Correspondence and requests for materials should be addressed to L.F.L.

Peer review information Nature Communications thanks Frank DeLeo and the other, anonymous, reviewer(s) for their contribution to the peer review of this work. Peer reviewer reports are available.

Reprints and permission information is available at http://www.nature.com/reprints

Publisher's note Springer Nature remains neutral with regard to jurisdictional claims in published maps and institutional affiliations.

(c) (i) Open Access This article is licensed under a Creative Commons cc. Attribution 4.0 International License, which permits use, sharing, adaptation, distribution and reproduction in any medium or format, as long as you give appropriate credit to the original author(s) and the source, provide a link to the Creative Commons license, and indicate if changes were made. The images or other third party material in this article are included in the article's Creative Commons license, unless indicated otherwise in a credit line to the material. If material is not included in the article's Creative Commons license and your intended use is not permitted by statutory regulation or exceeds the permitted use, you will need to obtain permission directly from the copyright holder. To view a copy of this license, visit http://creativecommons.org/ licenses/by/4.0/.

(C) The Author(s) 2020 